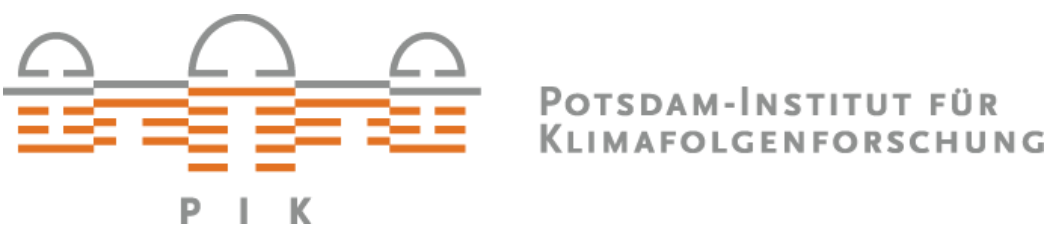

Originally published as:

Mouratiadou, I., Biewald, A., Pehl, M., Bonsch, M., Baumstark, L., Klein, D., Popp, A., Luderer, G., Kriegler, E. (2016). The impact of climate change mitigation on water demand for energy and food: an integrated analysis based on the Shared Socioeconomic Pathways. Environmental Science and Policy, 64: 48-58.

DOI: $\underline{10.1016 / \text { i.envsci.2016.06.007 }}$ 


\section{The impact of climate change mitigation on water demand for energy and food: an integrated analysis based on the Shared Socioeconomic Pathways}

Ioanna Mouratiadou*a, Anne Biewald ${ }^{\mathrm{a}}$, Michaja Pehl ${ }^{\mathrm{a}}$, Markus Bonsch ${ }^{\mathrm{a}}$, Lavinia Baumstark ${ }^{\mathrm{a}}$, David Klein $^{\mathrm{a}}$, Alexander Popp ${ }^{\mathrm{a}}$, Gunnar Luderer ${ }^{\mathrm{a}}$, Elmar Kriegler ${ }^{\mathrm{a}}$

${ }^{\text {a }}$ Potsdam Institute for Climate Impact Research, PO Box 601203, 14412 Potsdam, Germany

* Corresponding author: mouratiadou@pik-potsdam.de; Potsdam Institute for Climate Impact Research, PO Box 6012 03, 14412 Potsdam, Germany; +49 (0) 3312882687

\section{Abstract}

Climate change mitigation, in the context of growing population and ever increasing economic activity, will require a transformation of energy and agricultural systems, posing significant challenges to global water resources. We use an integrated modelling framework of the waterenergy-land-climate systems to assess how changes in electricity and land use, induced by climate change mitigation, impact on water demand under alternative socioeconomic (Shared Socioeconomic Pathways) and water policy assumptions (irrigation of bioenergy crops, cooling technologies for electricity generation). The impacts of climate change mitigation on cumulated global water demand across the century are highly uncertain, and depending on socioeconomic and water policy conditions, they range from a reduction of $15,000 \mathrm{~km}^{3}$ to an increase of more than $160,000 \mathrm{~km}^{3}$. The impact of irrigation of bioenergy crops is the most prominent factor, leading to significantly higher water requirements under climate change mitigation if bioenergy crops are irrigated. Differences in socioeconomic drivers and fossil fuel availability result in significant differences in electricity and bioenergy demands, in the associated electricity and primary energy mixes, and consequently in water demand. Economic affluence and abundance of fossil fuels aggravate pressures on water resources due to higher energy demand and greater deployment of water intensive technologies such as bioenergy and nuclear power. The evolution of future cooling systems is also identified as an important determinant of electricity water demand. Climate policy can result in a reduction of water demand if combined with policies on irrigation of bioenergy, and the deployment of non-water-intensive electricity sources and cooling types.

Keywords: water demand; climate change mitigation; bioenergy; electricity; Shared Socioeconomic Pathways; water policy

\section{Acknowledgements}

The research leading to these results has received funding from the European Union's Seventh Framework Program FP7/2007-2013 under grant agreements $n^{\circ} 308329$ (ADVANCE) and $n^{\circ}$ 603542 (LUC4C). 


\section{Introduction}

Future water systems are confronted with multiple challenges emerging from the interplay of the complex and interrelated set of forces often referred to as the water-energy-land-climate nexus. Agriculture is the largest user of the world's freshwater resources, consuming yearly $70 \%$ of all abstracted water (Rost et al., 2008) and resulting locally in severe water scarcity. Water is also a key input of most energy production and conversion processes, and in particular cooling for electricity generation. Electricity sector abstractions can be in the range of $40 \%$ of abstracted freshwater resources in industrialized countries (Byers et al., 2014) and insufficient water availability for energy supply systems is already apparent in various locations, such as the US (Feeley III et al., 2008). A world population expected to grow to $8.5-10$ billion $^{1}$ by 2050 (KC and Lutz, 2014; UN, 2015) and ever increasing economic growth will increase the pressure on energy, land, and water systems and add to the challenge.

In addition, as the energy and agricultural sectors are major greenhouse gas emitters, a substantial reduction of their emissions in order to mitigate climate change requires systems transformations that can pose further challenges regarding the use of water, land, and energy resources. Large scale bioenergy production, identified as an important option for reaching ambitious climate change mitigation goals (Rose et al., 2014), can put significant pressure on land and water resources (Beringer et al., 2011; Berndes, 2002; Bonsch, 2014). Further, the role of electricity is likely to become more prominent under climate change mitigation (Williams et al., 2012), resulting in increased water demand for power plant cooling purposes. The technology mix for achieving decarbonization of electricity systems consists of a combination of technologies, such as nuclear, fossils or biomass with carbon capture and storage (BECCS), and renewable sources (Krey et al., 2014; Luderer et al., 2014) characterized by diverse water requirements and thus impacts on water resources (Kyle et al., 2013).

Given the importance of the water-energy-land-climate nexus for sustainable climate and water resources planning, several studies have made attempts of its exploration. Some studies analyse water demand across sectors and socioeconomic scenarios (e.g. Alcamo et al., 2007; Hanasaki et al., 2013) using hydrological models with detailed representations of water resource systems and stylized representations of water demand. Another category of studies use integrated assessment models (IAMs) with detailed explicit representations of energy and land use systems. These models, by including comprehensive descriptions of energy carriers and conversion technologies, and potentially also land use dynamics, can better capture the underlying structural patterns of changes in energy and agricultural water demand. Several IAM studies focus on the energy-land use (e.g. Klein et al., 2014; Popp et al., 2014a), the water-land use (e.g. Bonsch et al., 2014; Chaturvedi et al., 2015) or the water-energy interactions (Davies et al., 2013; Kyle et al., 2013; Bijl et al., 2016; Fricko et al., 2016), yet the implications of combined socioeconomic and

\footnotetext{
${ }^{1}$ Future population projections range due to differences in the employed narratives and methods. The UN 2015 revision reports a projection of 9.7 billion of global population by 2050, while KC and Lutz (2014) project this to be about $8.5,9.2$ or 10 billion depending on the adopted narrative.
} 
mitigation assumptions across the full nexus is underexplored. One exception is the study of Hejazi et al. (2014), which investigates changes in water demand across the nexus under different socio-economic conditions, but does not explore the implications of such conditions under stringent mitigation scenarios.

This paper adds to the literature by providing a systematic exploration of the impact of socioeconomic assumptions and selected water policies on the effects of climate change mitigation on water demand, using an IAM approach across the water-energy-land-climate nexus. This allows us to consider explicitly the most important determinants of the effects of climate change mitigation on water use, namely demand patterns, the supply composition, and the water use intensity of electricity and agricultural systems. We investigate these effects with the use of three alternative Shared Socioeconomic Pathways (SSPs) ${ }^{2}$ (O'Neill et al., 2015), encapsulating profound differences regarding the underlying food and energy demand and supply dynamics, and therefore the associated challenges to mitigation. We explore the combined social and biophysical aspects of the nexus focusing on key systems interactions, such as water demand for electricity and agricultural production, and bioenergy and electricity demand for climate change mitigation. Further, we investigate the effects of two important dimensions of water policy: the irrigation of bioenergy crops and the shares of cooling technologies for power generation. By combining socioeconomic and water policy assumptions we demonstrate the uncertainty associated with the impacts of climate change mitigation on water use.

\section{Methodology}

\subsection{The LPJmL-MAgPIE-REMIND framework}

Our analysis uses the LPJmL-MAgPIE-REMIND integrated modelling framework (Popp et al., 2011, Figure 1), based on three coupled models representing different aspects of the water-energyland-climate nexus. LPJmL (Rost et al., 2008) is a global dynamic vegetation and hydrology model. MAgPIE (Biewald et al., 2014; Popp et al., 2014b) is a land use model representing costs of agricultural production, food and bioenergy demand, and land and water constraints. The REMIND model (Luderer et al., 2013; Mouratiadou et al., 2016) is a multi-regional model incorporating the economy, the climate system and a detailed representation of the energy sector. The MAgPIE-REMIND models are coupled in order to establish equilibrium of bioenergy ${ }^{3}$ and greenhouse gas emissions markets in an iterative procedure (see Bauer et al., 2014; Kriegler et al., 2016 for details). Establishing the simultaneous equilibrium of bioenergy and emissions markets allows addressing, beyond model boundaries, the trade-off between emissions savings from

\footnotetext{
${ }^{2}$ The SSPs reflect the socioeconomic component of the new scenario framework for climate change research (van Vuuren et al., 2014). This framework aims to facilitate the production of shared scenarios among the community carrying out research on climate change impacts, adaptation, and mitigation, and combines pathways of socioeconomic development with pathways of future radiative forcing and climate changes (van Vuuren et al., 2014). Further details are provided in section 2.3.

3 In the REMIND-MAgPIE scenarios, future bioenergy demand is dominated by second generation purpose-grown biomass.
} 
bioenergy in the energy sector and potential additional emissions from bioenergy production in the land use sector. More generally, it allows identifying the optimal combination of land- and energy-based mitigation options, including the optimal extent of bioenergy production which has important implications for water demand. The climate outcomes of the resulting emission pathways of the two models are estimated by the MAGICC model (Meinshausen et al., 2011).

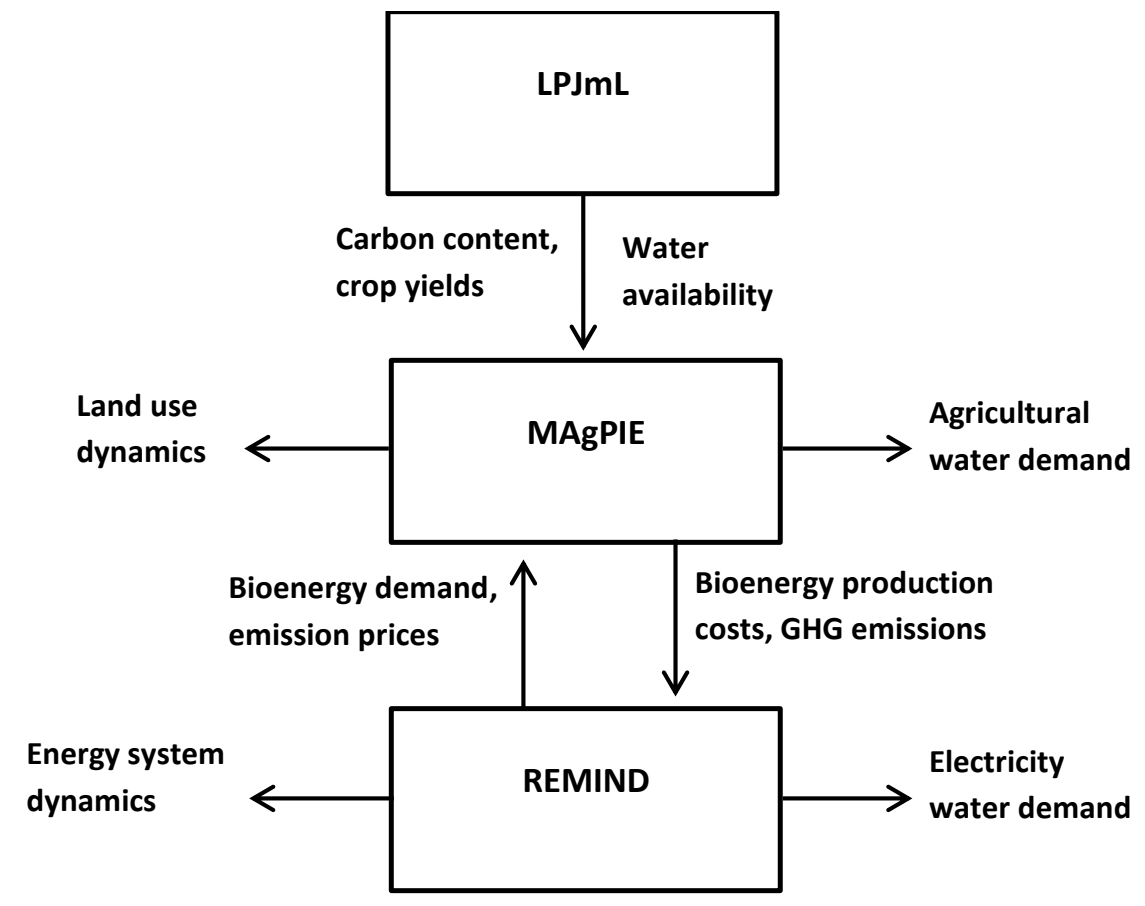

Figure 1: Information flow within the LPJmL-MAgPIE-REMIND modelling framework. Adapted from Popp et al. (2011).

The grid-based dynamic vegetation model LPJmL provides the agro-economic land and water use model MAgPIE with several biophysical inputs. Crop yields under rainfed and irrigated conditions are provided for 16 food crops and two bioenergy crops. Also, available water and the amount of irrigation water that needs to be applied to a field are provided on a 0.5 degree grid basis. Irrigation water requirements are estimated as the soil water deficit below optimal plant growth (Rost et al., 2008) and corrected for losses from source to fields. For each river basin, surface, lateral and seepage groundwater runoff are added to grid cell runoff and subsequently are available for downstream reuse, routed along the river network (Jägermeyr et al., 2015).

Agricultural water demand for irrigated crop and bioenergy production is determined endogenously in MAgPIE based on irrigation cost-effectiveness and water availability. Irrigated crop production requires irrigation infrastructure for water distribution and application. The initial pattern of area equipped for irrigation is taken from the AQUASTAT database (Siebert et al., 2007). During the optimization process, the model can endogenously deploy additional irrigation infrastructure (not including building reservoirs). Irrigation costs comprise investment costs for the deployment of additional irrigation infrastructure as well as annual costs for operation and maintenance of irrigation systems.

The REMIND model features an elaborate representation of water demand for electricity production, taking explicitly into account the age structure of thermal power plants and power 
plant thermal efficiencies. Our estimate of water demand for electricity represents requirements associated to cleaning, cooling, and other process related needs (e.g. flue gas desulfurization) (Macknick et al., 2011), and is based on the mix of electricity production technologies, the shares of cooling technologies, the water withdrawal and water consumption intensities, the vintage structures and the power plant thermal efficiencies. All four principal cooling systems, namely once-through (freshwater or sea water), wet tower, dry tower, and pond cooling are considered ${ }^{4}$.

Further details on our modelling framework are provided in the Supplementary Material (SM).

\subsection{Water Use Indicators}

The most common water use indicators are water withdrawal and water consumption. Withdrawal is defined as the amount of water removed from the ground or diverted from a water source for use, while water consumption refers to the amount of water that is transpired, evaporated, incorporated into products or crops, or otherwise removed from the water environment (Kenny et al., 2009). In other words, while water withdrawal corresponds to the total water taken from a source, water consumption represents the part of water withdrawal that is not returned back to the source (Feeley III et al., 2008). The two indicators encapsulate different impacts of water demand on the water environment and highlight different aspects of the choice of electricity and cooling technologies regarding their impacts on electricity water requirements. A discussion of these aspects is provided in the SM.

Both of these indicators feature in our analysis. In the MAgPIE model, agricultural water use is represented in terms of water abstractions for irrigation, which corresponds to the water withdrawal indicator. In the REMIND model, water demand for electricity is distinguished between water withdrawal and water consumption. The water requirements for the production of bioenergy crops are part of agricultural water demand in the MAgPIE model. Hydropower uses water in situ and is therefore assumed to be associated only to water consumption due to evaporation and seepage. The water volumes associated to sea water are not reported as part of our water use indicators which focus on freshwater use.

\subsection{Scenarios and application of Shared Socioeconomic Pathways}

Our scenarios integrate three dimensions a) socioeconomic assumptions based on the SSPs; b) assumptions on the stringency of climate policy; c) assumptions on important water policy dimensions, including the irrigation of bioenergy crops and the shares of cooling technologies.

The SSPs are a key component of the new scenario framework for climate change analysis representing varying socioeconomic reference conditions (O'Neill et al., 2015; Kriegler et al., 2014). These varying pathways of future development are distinguished by socioeconomic features (e.g. population, economic development), natural resource developments (e.g. fossil fuel availability) and challenges to mitigation and adaptation (O'Neill et al., 2014). In this paper, we focus on the three (out of five) SSPs, which best represent different levels of challenges to

\footnotetext{
${ }^{4}$ An extensive characterization of the different cooling types can be found in Byers et al. (2014).
} 
mitigation: a) SSP1: Sustainability - Taking the green road (low challenges to mitigation); b) SSP2: Middle of the Road (moderate challenges to mitigation); c) SSP5: Fossil-fuelled development - Taking the highway (high challenges to mitigation). A brief characterization of these three SSPs is provided in Table 1, and a more extensive description in the SOM and in O'Neill et al. (2015). The SSPs can be effectively combined with different Representative Concentration Pathways (RCPs) (van Vuuren et al., 2011) using a scenario matrix architecture (van Vuuren et al., 2014). Here we investigate the effects of baseline assumptions, which are represented by reference scenarios with no climate policy constraints, as well as the implications of stringent climate action corresponding to the RCP 2.6 scenario.

Table 1: Key characteristics of the SSPs ${ }^{5}$

\begin{tabular}{l|cc|cc|cc}
\hline Scenario & \multicolumn{3}{|c|}{ SSP1 } & \multicolumn{2}{c|}{ SSP2 } & \multicolumn{2}{c}{ SSP5 } \\
& 2050 & $\mathbf{2 1 0 0}$ & $\mathbf{2 0 5 0}$ & $\mathbf{2 1 0 0}$ & $\mathbf{2 0 5 0}$ & $\mathbf{2 1 0 0}$ \\
\hline Population (billion) & 8.4 & 6.9 & 9.1 & 9 & 8.5 & 7.4 \\
$\begin{array}{l}\text { GDP in baseline (thousand } \\
\text { billion US2005\$/yr) }\end{array}$ & 174 & 331 & 145 & 315 & 229 & 670 \\
Total food demand (EJ) & 38.9 & 29.8 & 42.2 & 45.6 & 44.2 & 46.3 \\
$\begin{array}{l}\text { Total energy demand in } \\
\text { baseline (EJ/yr) }\end{array}$ & 542 & 482 & 635 & 869 & 869 & 1220 \\
$\begin{array}{l}\text { Climate forcing in baseline } \\
\left(\mathbf{W} / \mathbf{m}^{2}\right)\end{array}$ & 4.1 & 5.2 & 4.3 & 6.9 & 4.9 & 8.9 \\
\hline
\end{tabular}

Further, we vary two uncertain but highly important dimensions of future water policy. The first dimension relates to the irrigation of bioenergy crops, where we assume either a full restriction or no restriction on the irrigation of these crops. The second dimension pertains to the shares of cooling technologies for each electricity technology. We employ a pessimistic scenario of static (equal to the 2005 base year) cooling shares and a scenario of dynamic in time cooling shares, where there is a shift away from the construction of once-through cooling systems, towards mainly recirculating and to some extent dry cooling technologies. Such trends are already observed in the United States, Europe, and China due to concerns over water availability and environmental protection (Davies et al., 2013). Values on the two sets of cooling shares have been deduced from Kyle et al. (2013).

In total, we investigate 24 scenarios (SM Table 2) by varying the different dimensions as follows: a) three SSPs: SSP1, SSP2, SSP5; b) two climate policy variations: baseline with no climate policy (Base) and RCP2.6 (Pol); c) four water policy variations: unrestricted irrigation of bioenergy (irr)

\footnotetext{
${ }^{5}$ Population, GDP, total food demand and increase of protected areas are exogenous scenario features, while total energy demand and forcing levels are model results. These figures may differ slightly to those of the final SSPs, because they correspond to a slightly earlier revision of the LPJmL-MAgPIE-REMIND modelling framework.
} 
or rainfed only bioenergy production ( $r n f)$, with each of these two cases combined with either static (stat) or dynamic in time (dyn) shares of power plant cooling technologies.

\subsection{Limitations of the modelling framework}

Our modelling framework currently lacks a representation of water demand for domestic and manufacturing purposes and for energy beyond electricity, as well as the representation of a market-based decision making mechanism of water allocation (such as water pricing or water markets) across different sectors. We therefore assume a rule-based prioritization of water allocation for non-agricultural purposes, as very much observed in reality, and impose this assumption in the MAgPIE model by allowing only a percentage of available water to be used for agricultural purposes. This percentage is set to $50 \%$ based on the fact that globally about $30 \%$ of blue water withdrawals are used for non-agricultural purposes (FAO, 2014) and on the assumption that a minimum of $20 \%$ of available water cannot be abstracted for technical as well as environmental reasons. The implications of this assumption are explored via a sensitivity analysis (see section 3.2.1).

The REMIND model does not consider constraints on water quantity and quality, although such constraints might well be a limiting factor to the expansion of water-intensive technologies. The effort to properly represent water availability constraints in complex global IAMs involves representing the current and future spatial allocation of power plants across the globe and achieving major advancements in downscaling and optimization processes in order to allow for an optimization at a finer scale. As a consequence, the majority of studies of the current generation of IAMs assessing water demand trends at a global scale (e.g. Bijl et al., 2016; Davies et al., 2013; Fricko et al., 2016; Hejazi et al., 2014; Kyle et al., 2013) still lack a representation of water quantity and quality constraints. The incorporation of such features in our framework is work in progress.

Water availability constraints, along with energy use considerations, the costs and other technoeconomic characteristics of different cooling types, such as their impact on conversion efficiencies, are in essence the decision criteria utilized by power plant managers in choosing the appropriate cooling system. These features are not considered in our study, which nevertheless adopts transparent assumptions in the evolution of cooling systems in the future. The approach to rely on exogenous assumptions on the evolution of cooling systems is one of the most common approaches encountered in the literature (e.g. Bijl et al., 2016; Byers et al., 2014; Davies et al., 2013; Kyle et al., 2013). 


\section{Results}

\subsection{Effects of climate change mitigation}

\subsubsection{Irrigation water demand}

Stringent climate change mitigation has profound implications for total water demand, with irrigation of bioenergy being the water use that is impacted the most (Figure 2). In the baseline scenario, the limited demand for bioenergy results in negligible water requirements, but in the policy scenario approximately an additional $2,700 \mathrm{~km}^{3}$ of water per year are needed by the end of the century. This notably high increase, in the range of todays' global agricultural water withdrawals (Shiklomanov, 2000), is in line with findings of other studies which report that water requirements for irrigated bioenergy under climate change mitigation can be in the same magnitude as current agricultural water requirements (Beringer et al., 2011; Berndes, 2002) or even twice as high (Chaturvedi et al., 2015).

The radical increase in water use for bioenergy is due to the increase of bioenergy demand resulting from ambitious climate policies, reaching in 2100 almost $400 \mathrm{EJ} / \mathrm{yr}$ as opposed to less than $100 \mathrm{EJ} / \mathrm{yr}$ in the baseline scenario (Figure 3). High levels of BECCS deployment in stringent climate stabilization scenarios are common in the literature, since in most model studies it is the main technique adopted for the generation of negative emissions (Clarke et al., 2014). The significant increase in total bioenergy demand under climate policy leads to a huge expansion of the total area devoted to bioenergy production (29 million ha in 2100 in the baseline case and 511 million ha in the policy case). Also, since land is scarce and average yields of irrigated bioenergy production crops are about 11 times as high as rainfed yields in 2100 , there is a shift towards higher shares of irrigated bioenergy production in the policy scenario, which increases from 7 million ha in the baseline to 199 million ha.

Contrary to bioenergy production, the impacts of climate policy on irrigation water requirements for non-energy crops (food crops, material crops, and fodder) are small (Figure 2). In both scenarios, water withdrawals increase from about 2,500 km3/yr to about 3,000 km3/yr in the course of the century due to the increasing exogenous SSP-specific food demand. Water withdrawals are slightly higher in the policy scenario until 2040 and about $200 \mathrm{~km}^{3} / \mathrm{yr}$ lower in 2100. The latter is due to investments into yield increasing technological change, which is one of the possible measures to fulfil the exogenously given food and bioenergy demand in the MAgPIE model. In the policy scenario, higher bioenergy demand in the second half of the century, results in higher investments in technological change (SM Figure 4), which increase water use efficiency, leading thus to a smaller demand for irrigation water per unit of output (Bonsch et al., 2014). 
Changes in Water Use (SSP2 Pol minus SSP2 Base)
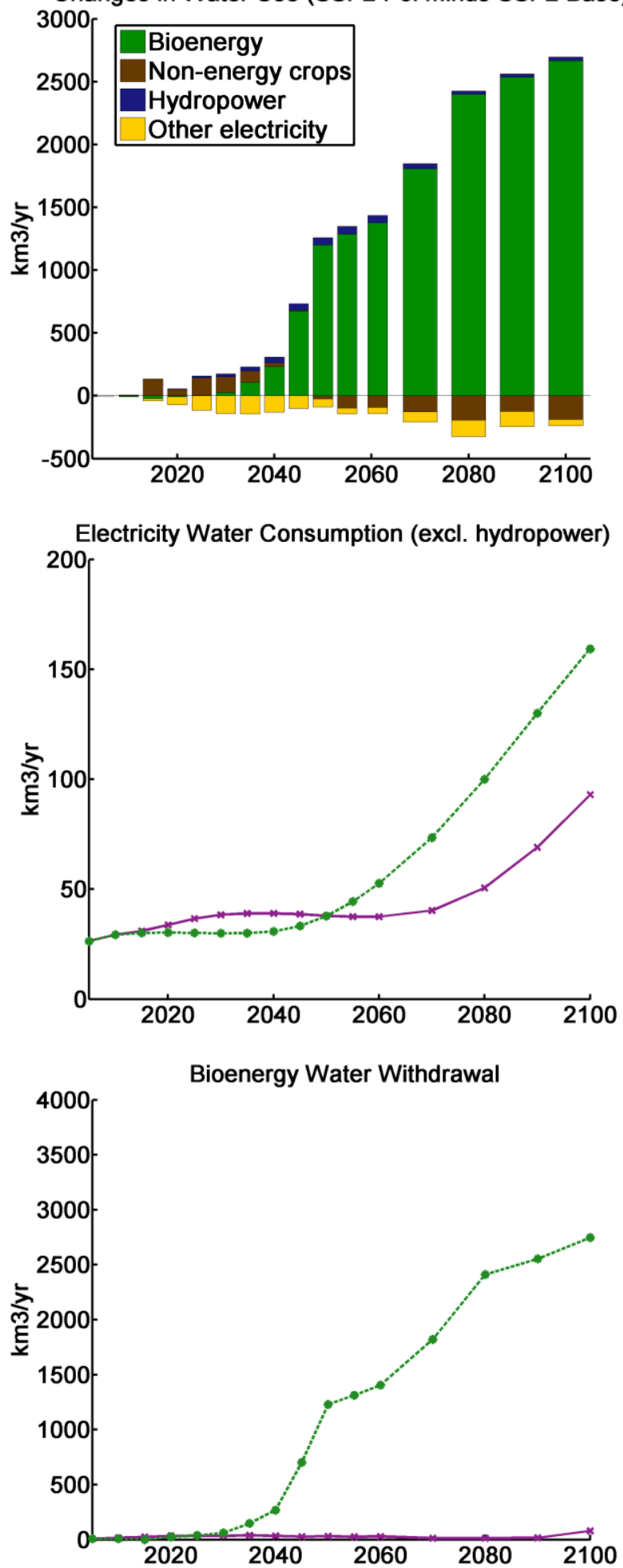
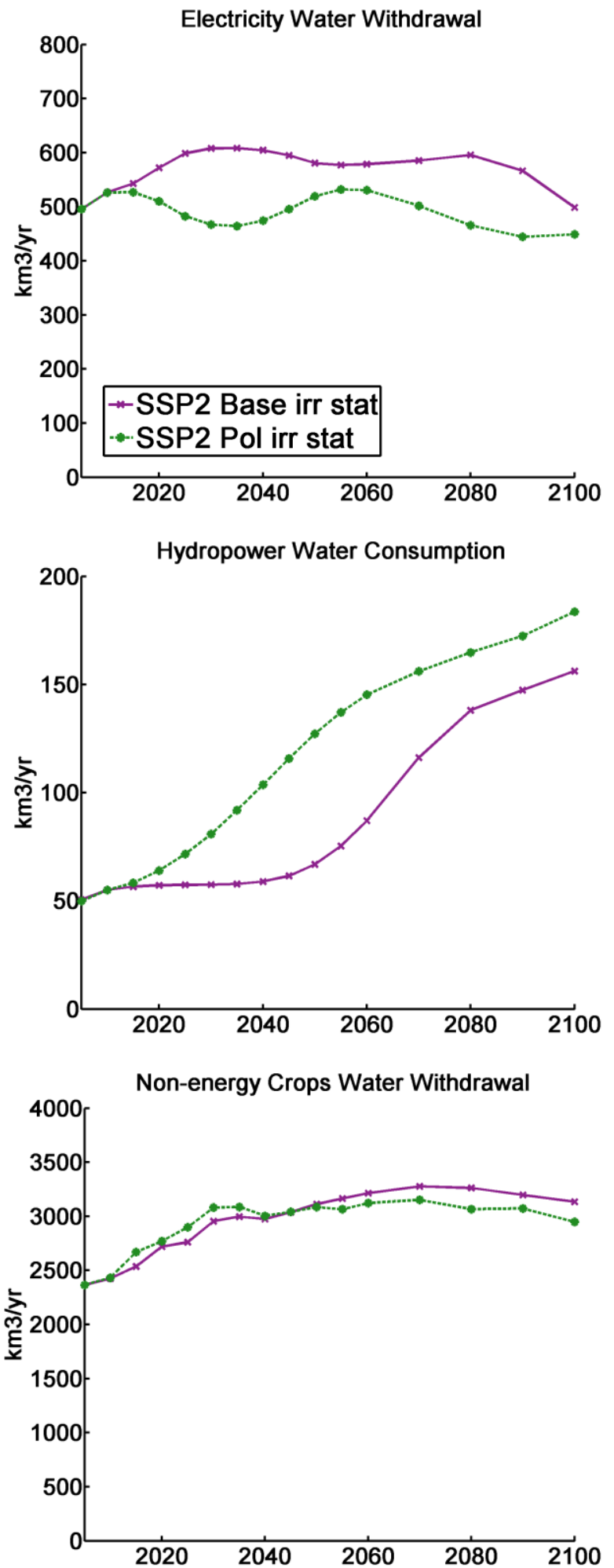

Figure 2: Differences in water use between the SSP2 baseline and policy scenarios. In the top left panel, water use is represented by water withdrawals with the exception of hydropower which is associated to water consumption and negative numbers indicate lower values in the SSP2 Pol scenario compared to the SSP2 Base scenario.

On the down side, additional necessary investment into technological change increases overall production costs. This leads to increases in consumer prices, which in 2100 are increased by about 
$50 \%$ between the baseline and policy scenarios for non-energy crops and more than doubled for bioenergy crops (SM Figure 4). Prior to 2040, pressure on land for the production of bioenergy crops is limited and therefore no significant investments in technological change are observed. Nevertheless, the introduction of a carbon price leads to a significant increase in forest land, which leads to increased competition for land, and motivates the expansion of non-energy crops into irrigated areas (SM Figure 10) which correspond to higher yields but also somewhat higher water requirements in the climate policy scenario compared to the baseline.

\subsubsection{Electricity water demand}

Electricity water withdrawals are about $500 \mathrm{~km} 3 / \mathrm{yr}$ in early and also late century in both the baseline and policy scenarios (Figure 2). Electricity water withdrawals relate to the interplay of changes in total electricity demand and the water intensity of electricity production.

In the baseline, electricity demand more than doubles by 2030 and more than quadruples by 2080 compared to base year levels (Figure 3, SM Figure 2). At the same time, the water intensity of electricity output is constantly reduced (SM Figure 2) due to changes in the electricity mixes, and also improvements in the intensity factors of individual technologies. Specifically, there is a shift from coal and gas power plants towards non-biomass renewables (Figure 3), which are associated with no (e.g. wind, solar photovoltaics) or moderate (CSP - Concentrated Solar Power) water withdrawals (SM Table 1). Another reason for the improvement of the electricity water intensity over time, are the improvements of water intensity factors of individual technologies (e.g. coal) due to thermal efficiency improvements and a transition towards more water efficient technologies (e.g. from pulverized coal towards combined cycle and combined heat and power).

Water withdrawals for electricity are moderately lower in the mitigation scenario (Figure 2). That effect is due to changes in the electricity mixes resulting in water intensity improvements that prevail over significant increases in electricity demand tending to increase water withdrawals. Specifically, total demand for electricity is similar to baseline levels until 2050 but almost $40 \%$ higher in 2100 (Figure 3, SM Figure 2), due to electricity being a carrier that is typically easier to decarbonize compared to liquids, gases or solids. On the other hand, the changes in the composition of the electricity mix decrease water withdrawal per unit of electricity output more drastically in the mitigation scenario (SM Figure 2), due to a more intensive substitution of fossil power plants by renewables, in comparison to the substitution occurring in the baseline scenario Figure 3).

On the contrary to water withdrawals, water consumption for electricity is higher in the mitigation scenario (Figure 2). That is partly due to an increase in the use of hydropower (Figure 3, SM Figure 3) that is associated with significant evaporative losses. Additionally, the significant higher shares of solar CSP (Figure 3), a technology with high water consumption requirements (SM Table 1), gives rise to a further increase in consumptive electricity water demand in the second half of the century. Previous studies also observe lower electricity water withdrawals under mitigation scenarios despite increasing electricity demand, but higher water consumption (e.g. Kyle et al., 2013). 

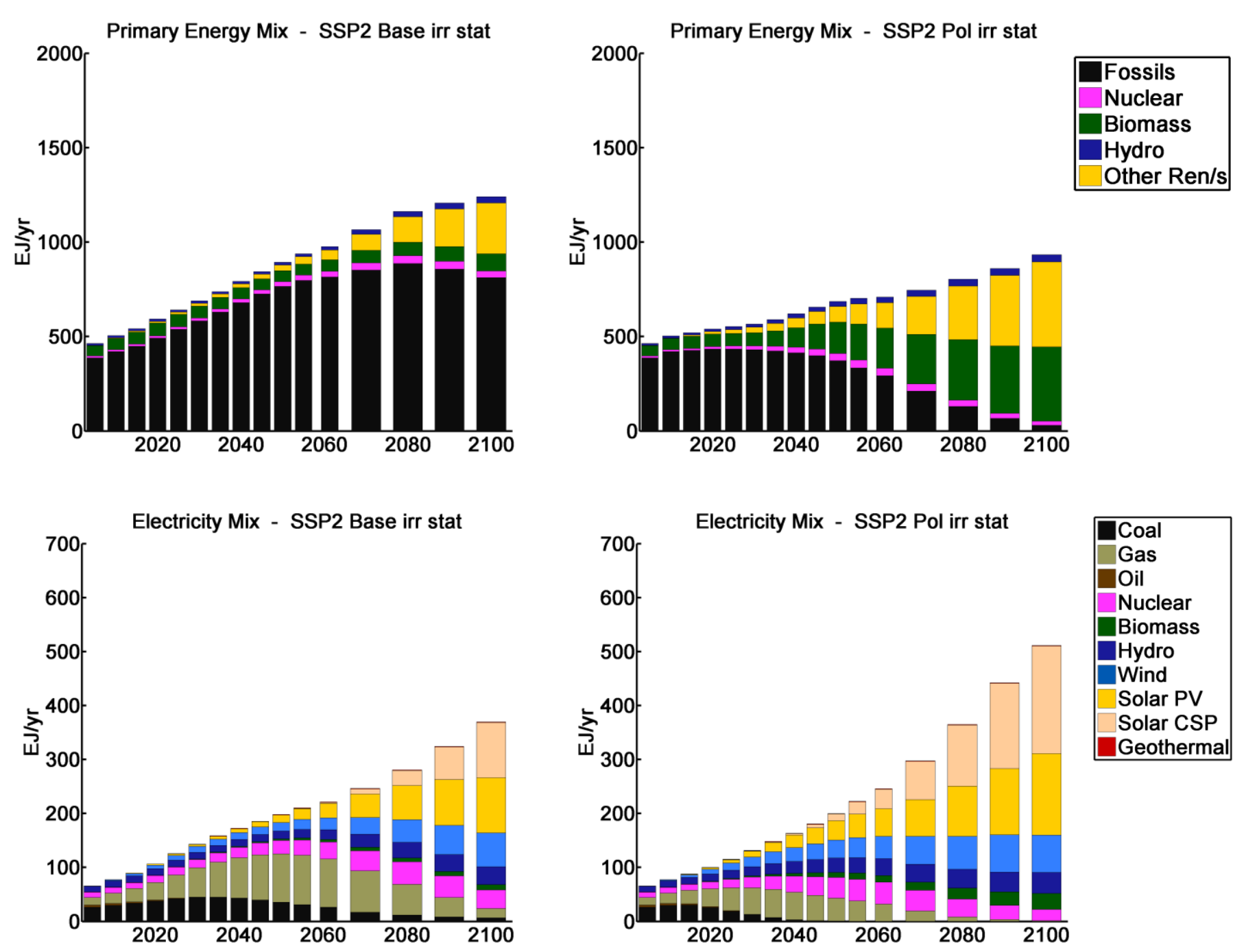

\begin{tabular}{|l|}
\hline Coal \\
Gas \\
Oil \\
Nuclear \\
Biomass \\
Hydro \\
Wind \\
Solar PV \\
Solar CSP \\
Geothermal \\
\hline
\end{tabular}
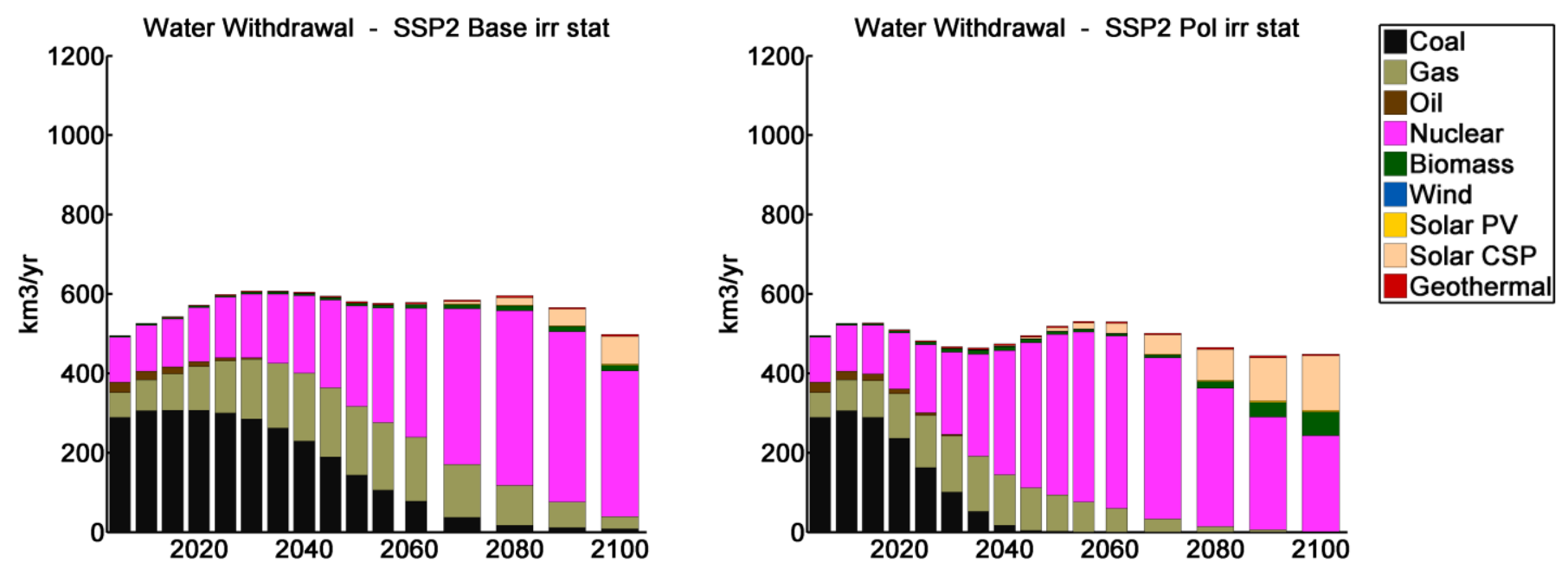

Figure 3: Primary energy, electricity, and electricity water withdrawal mixes for the SSP2 baseline and policy scenarios. 


\subsection{Effects of Shared Socioeconomic Pathways}

\subsubsection{Irrigation water demand}

Among all water uses, the difference in water withdrawals between the baseline and the policy scenarios is most pronounced for irrigated bioenergy in all SSPs (Figure 4). These differences are almost twice as high in SSP5 compared to SSP1, and proportional to differences in demand for bioenergy, which are also almost twice as high in SSP5 compared to SSP1 (Figure 4).

Cumulated water use for food crops over the century is lower with climate policy for all SSPs (Figure 4), due to technological change improvements that increase water productivity, also discussed in section 3.1.1. The price increases for non-energy crops associated to these technological improvements differ across SSPs and are lower in the case of SSP1 where overall competition for land and water resources is smaller, and higher in the high pressure SSP5 (SM Figure 4). Further, in SSP2 and SSP5, the pressure on land and water resources is comparatively high due to higher overall demand for food, livestock, and energy related products. That leads to land expansion into irrigated, but relatively unproductive areas, thus partly off-setting the water savings effect of technological change. In SSP1, competition for land and water is smaller, enabling thus to satisfy non-bioenergy demand without expanding further into irrigated areas and therefore resulting in greater water savings than the other two scenarios.

When exploring the sensitivity of the MAgPIE assumption that only half of available water is accessible to agricultural production, we find that our core results in relative terms remain unaffected. Changing the fraction of available water reserved for non-agricultural uses to either 0.4 or 0.6 , as opposed to 0.5 , results in an about $10 \%$ increase or decrease of water withdrawn for bioenergy production, respectively (SM Figure 5). Although this is significant, our key result that water withdrawals for irrigated bioenergy could be dramatically increased by climate change mitigation remains unaffected, and so does the relative difference of this effect between SSPs. In reality, the availability of water for irrigating bioenergy crops is very likely to be determined by regulation on the irrigation of bioenergy crops, which as we show in section 3.3.1 is the most crucial factor. 


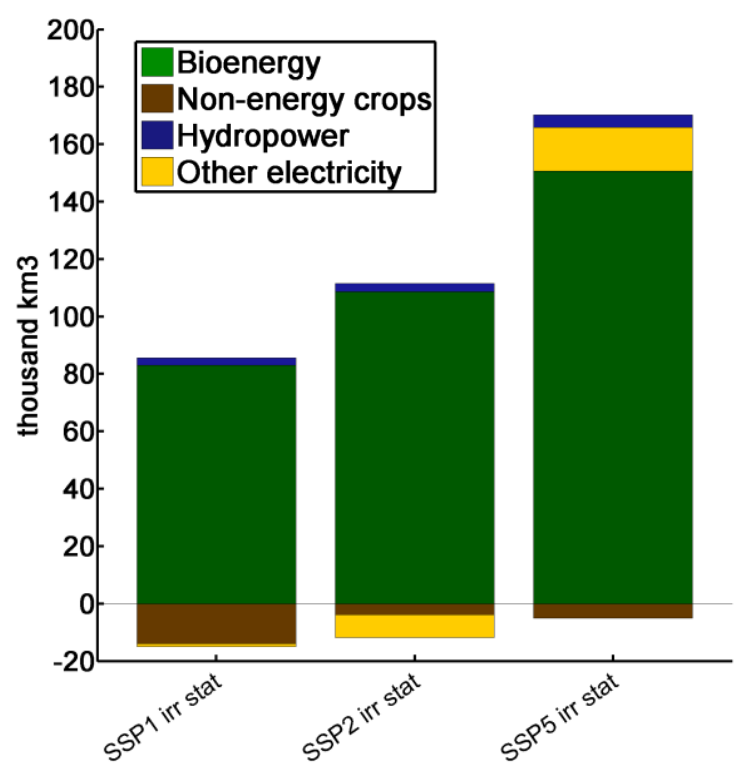

Cumulated Water Withdrawals (2005-2100)

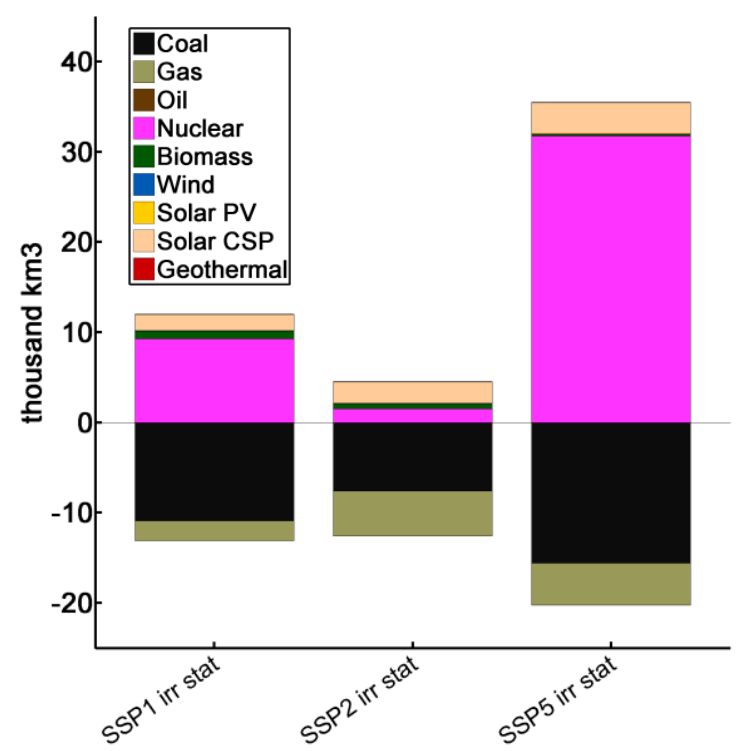

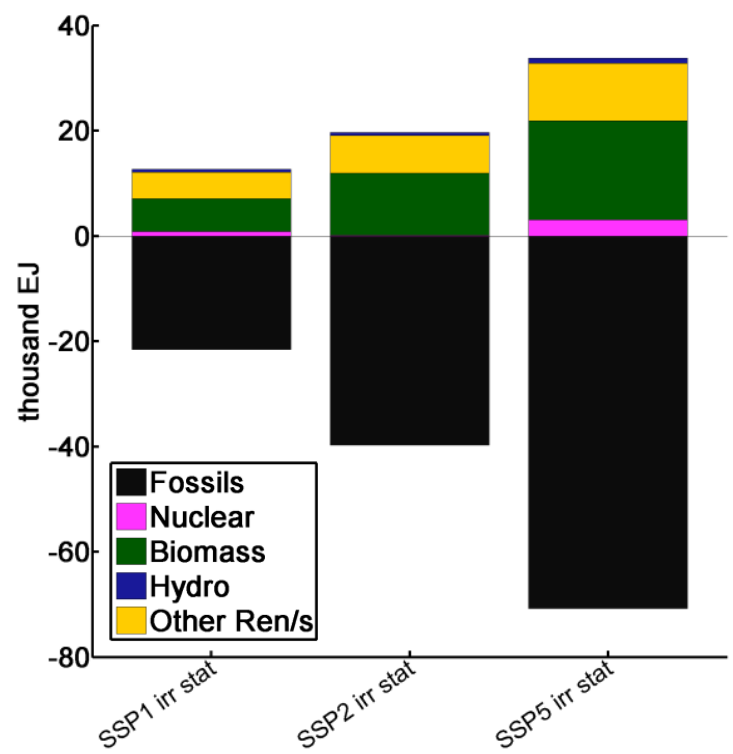

Cumulated Electricity (2005-2100)

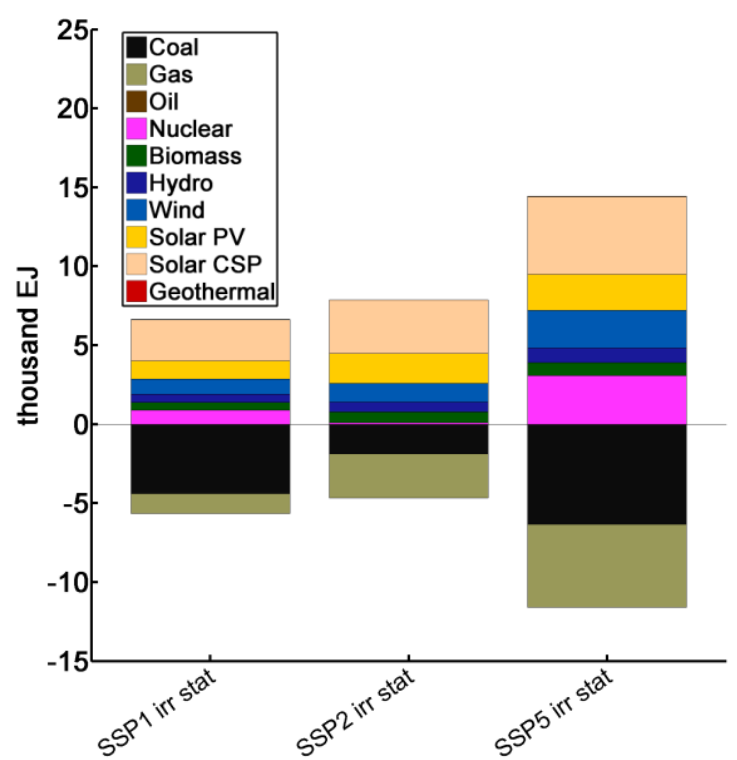

Figure 4: Differences in cumulated water and energy use between the baseline and policy scenarios across SSPs. In the top left panel water use is represented by water withdrawals with the exception of hydropower which is associated to water consumption. Negative numbers indicate lower values in the policy scenarios compared to the equivalent baseline scenarios.

\subsubsection{Electricity water demand}

Water withdrawals for electricity production are reduced, compared to the baseline scenario, in the SSP1 and SSP2 policy scenarios, but increased in SSP5 (Figure 4). The magnitude of change is also different across SSPs, with SSP1 being characterized by minimal changes and SSP5 by significant ones.

One reason is the more pronounced increase in cumulated electricity demand under the SSP5 policy scenario, which is more than double of the increase observed in SSP1 (Figure 4, SM Figure 6). Additionally, and in contrast to the other two scenarios, the SSP5 baseline is associated with 
lower water withdrawal intensity than the SSP5 policy scenario (SM Figure 6) due to significantly higher gas shares, as opposed to coal and nuclear shares that are more dominant in the other two baseline scenarios (Figure 3, SM Figure 7, SM Figure 8) and that are characterized by higher water withdrawal intensities (SM Table 1). However, in the SSP5 policy scenario there is a dramatic increase in the use of water intensive nuclear generation in comparison to baseline levels, and this gives rise to the observed increase of water withdrawals. Water consumption also increases more drastically in SSP5 due to a more pronounced increase of hydropower and CSP, which are associated with high water consumption (SM Figure 9, SM Table 1).

In sum, in SSP5 in order to satisfy high energy demand while shifting away from a fossil-based system due to stringent climate change mitigation, a more pronounced increase of water intensive albeit carbon negative and carbon neutral options, such as BECCS, nuclear power, hydropower and solar CSP are augmenting significantly water demand.

\subsection{Effects of combined socioeconomic and water policy assumptions}

\subsubsection{Irrigation water demand}

The assumptions on irrigation of bioenergy crops are of utmost importance. Net water use is reduced under climate change mitigation for all SSPs if the irrigation of bioenergy crops is restricted, but dramatically increased otherwise (Figure 5). However, fulfilling the high bioenergy demand of the policy scenarios under such restrictions requires more land and higher investments in yield increasing technological change. Since bioenergy production cannot benefit from higher irrigated yields due to the associated restrictions, its production is shifted not only into rainfed but also into irrigated areas of non-energy crop production (SM Figure 10), reducing thus the associated water requirements for these crops. The higher investments into technological change, needed in order to increase land and water productivity, also result into lower water requirements for non-energy crops, mainly in the high pressure SSP5 scenario.

Restricting the irrigation of bioenergy crops has direct implications for bioenergy prices, which increase by about $20 \%$ (with some variation across scenarios and time steps) (SM Figure 11) as also shown by Bonsch et al. (2014). Food prices, and consequently the costs of food production, are minimally affected (SM Figure 11), since the associated water withdrawals do not change significantly (Figure 5).

\subsubsection{Electricity water demand}

Assumptions on the evolution of cooling shares in time have important implications for electricity water withdrawals (Figure 5). The effect of climate change mitigation on cumulated water withdrawals is significantly reduced for all SSPs when dynamic cooling shares are employed, due to the shift away from once-through cooling facilities. Since once-through cooling is associated with the highest water withdrawals, moving away from such cooling systems results in a reduction of the sensitivity of water withdrawals to transformations of the electricity mix and in particular the changes associated to thermoelectric power plants (SM Figure 12). On the other hand, electricity water consumption is not significantly affected by the assumptions on cooling shares 
(Figure 5). Nonetheless, the dynamic cooling shares scenarios result in slightly higher differences between baseline and policy scenarios, since recirculating cooling systems, that are associated to the highest water consumption factors, are increased.

Cumulated Water Use (2005-2100)
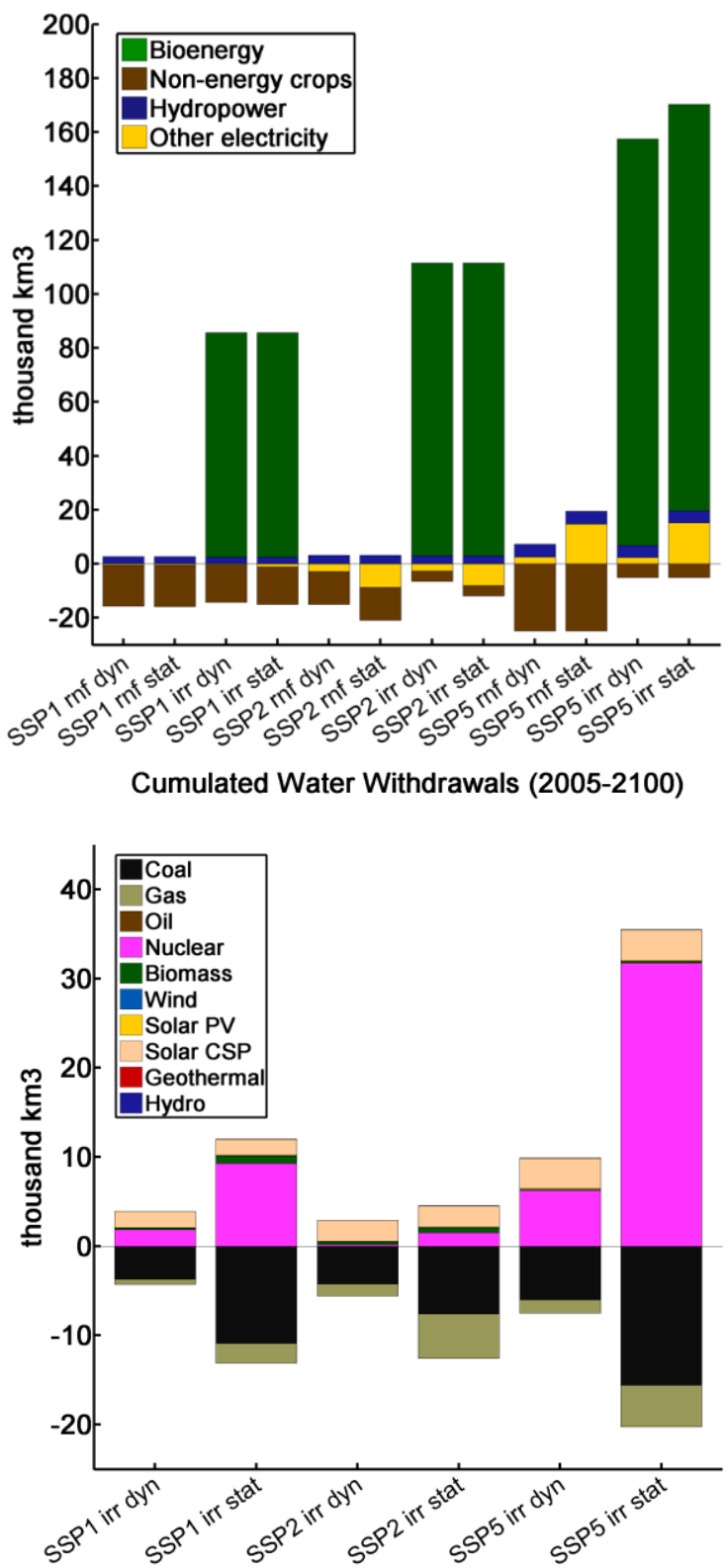

Cumulated Electricity Water Use (2005-2100)

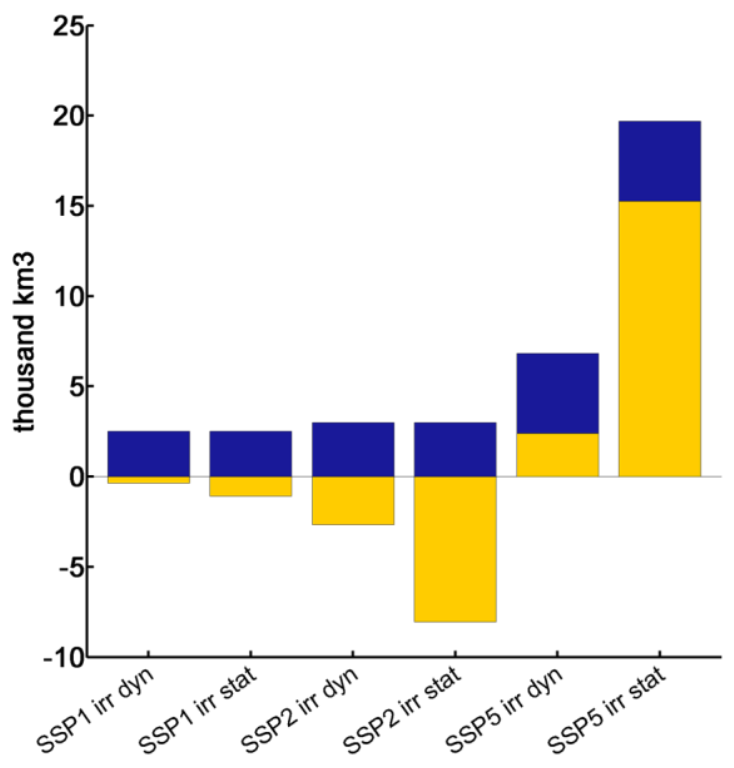

Cumulated Water Consumption (2005-2100)

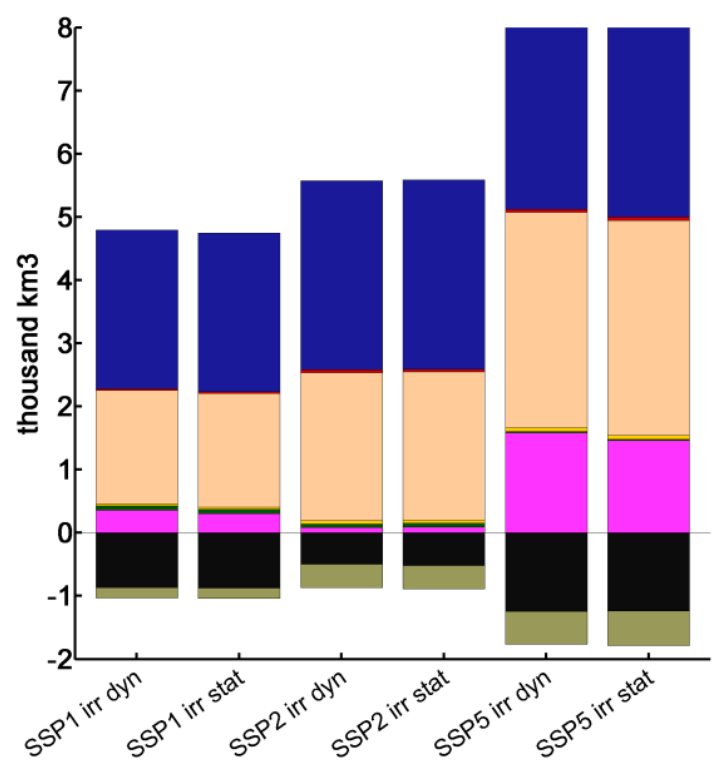

Figure 5: Differences in cumulated a) water use, b) electricity water use, c) electricity water withdrawal mixes, and d) electricity water consumption mixes between the Baseline and Policy scenarios across SSPs and water policy assumptions. In the top left panel, water use is represented by water withdrawals with the exception of hydropower which is associated to water consumption. Negative numbers indicate lower values in the Policy scenarios compared to the equivalent Baseline scenarios.

\section{Summary and Conclusions}

This paper investigates the impacts of climate change mitigation on freshwater use in the agricultural and electricity sectors under different socioeconomic and water policy assumptions via an integrated water-energy-land-climate nexus approach. We identified important differences 
on the effects of mitigation on water demand between SSPs, due to differences in demands for electricity and most importantly bioenergy and changes in electricity and primary energy mixes. Our results demonstrate the impact of socioeconomics, fossil fuel availability, climate and water policy for the future of water resources, highlight the uncertainty associated to these factors, and advocate their consideration for successful integrated water resources planning. Current research on policy integration acknowledges that sustainability solutions can only be effective via integrated approaches (Kua, 2007; Kua and Gunawansa, 2010). Our analysis allows identifying the key areas for policy integration across water and climate policy.

Economic affluence, high energy and food demand, and fossils abundance (SSP5) amplify water resource challenges under climate policy, due to a more radical shift towards higher shares of carbon free but more water intensive options. That involves mainly BECCS, but also nuclear power, hydropower, and solar CSP. Mitigation leads to a major increase in water used for bioenergy production in all SSPs, but the magnitude of this increase is almost halved in a sustainability-focused (SSP1), compared to a high demand and fossil-based, world (SSP5).

The effect of climate policy on electricity water withdrawals is highly sensitive to the deployment of nuclear power in the mitigation scenario. Water withdrawals for electricity are negatively affected by climate policy only in the SSP5 scenario, due to higher shares of nuclear power. In the other two SSPs, less pressing demand for electricity is satisfied by greater reliance on less water intensive technologies, such as solar photovoltaics and wind. This finding indicates that policydriven restrictions on the expansion of water intensive electricity technologies, such as nuclear, might have an important positive impact of the water balance of mitigation scenarios.

Irrespective of SSP assumptions, irrigated bioenergy production consumes the lion's share compared to other water uses. Our results are, thus, very sensitive to assumptions about the irrigation of bioenergy crops in the future, since climate policy results in significantly higher net water withdrawals compared to a no-climate policy world if bioenergy crops are irrigated. Even though future water withdrawals for irrigated bioenergy production as high as current global agricultural withdrawals appear to be technically feasible, the extent to which they may impair freshwater ecosystems needs to be further addressed, given that even the current levels of human exploitation of water resources pose a significant threat to aquatic ecosystems (Bonsch et al., 2014).

Increased competition for land due to higher bioenergy demand can push the production of nonenergy crops into less productive rainfed areas or lead to investments in additional technological change. The latter would increase overall water productivity and reduce irrigation requirements for non-energy crops. Nevertheless, these transformations that can be induced either by climate policy or due to restrictions on the irrigation of bioenergy come at a price. Climate policy increased bioenergy and consumer prices in all SSPs, but more dominantly in the high pressure SSP5.

Concerning electricity water demand, beyond the impact of electricity mix transformations, the evolution of future cooling systems was identified as another key determinant. A shift away from once-through towards recirculating cooling systems would significantly lessen the differences 
between baseline and climate change mitigation conditions regarding water withdrawals, but would increase those relating to water consumption. Therefore policy clarity on which are the most relevant water objectives to be met is needed.

In summary, climate policy can have synergies for water use if combined with policies on irrigation of bioenergy and electricity water use. Long-term policies on irrigation can only be successful if they take into account the possible effects of increased demand for bioenergy and the cascading effects on water resources. Economic considerations on the effects of food and bioenergy prices need to be taken into account in the design of such policies. Also, the source of power generation, such as wind power or solar photovoltaics versus more water-intensive nuclear, hydropower and CSP, but also the employed cooling systems, such as recirculating versus oncethrough systems, are important determinants of water demand. Therefore, policies on electricity water use are needed in order to counteract potentially negative effects induced by water-intensive carbon free technologies in localities prone to water scarcity.

\section{References}

Alcamo, J., Flörke, M., Märkel, M., 2007. Future long-term changes in global water resources driven by socio-economic and climatic changes. Hydrol. Sci. J. 52, 247-275.

Bauer, N., Klein, D., Luderer, G., et al., 2014. Climate change stabilization and the energy-land nexus. In: Proceedings of the 2014 International Energy Workshop. Beijing, China.

Beringer, T., Lucht, W., Schaphoff, S., 2011. Bioenergy production potential of global biomass plantations under environmental and agricultural constraints. GCB Bioenergy 3, 299-312.

Berndes, G., 2002. Bioenergy and water - the implications of large-scale bioenergy production for water use and supply. Glob. Environ. Change 12, 253-271.

Biewald A., Rolinski S., Lotze-Campen H., et al., 2014. Valuing the impact of trade on local blue water. Ecol. Econ. 101, 43-53.

Bijl, D.L., Bogaart, P.W., Kram, T., de Vries, B.J.M., van Vuuren, D.P., 2016. Long-term water demand for electricity, industry and households. Environ. Sci. Policy 55, Part 1, 75-86.

Bonsch, M., Humpenöder, F., Popp, A., et al., 2014. Trade-offs between land and water requirements for large-scale bioenergy production. Glob. Change Biol. Bioenergy 11-24.

Byers, E.A., Hall, J.W., Amezaga, J.M., 2014. Electricity generation and cooling water use: UK pathways to 2050. Glob. Environ. Change 25, 16-30.

Chaturvedi, V., Hejazi, M., Edmonds, J., et al., 2015. Climate mitigation policy implications for global irrigation water demand. Mitig. Adapt. Strateg. Glob. Change 20, 389-407.

Clarke, L., Jiang, K., Akimoto, K., et al., 2014. Assessing Transformation Pathways. In: Edenhofer, O., Pichs-Madruga, R., Sokona, Y., et al. (eds) Climate Change 2014: Mitigation of Climate Change. Contribution of Working Group III to the Fifth Assessment Report of the Intergovernmental Panel on Climate Change. Cambridge University Press, Cambridge and New York.

Davies, E.G.R., Kyle, P., Edmonds, J.A., 2013. An integrated assessment of global and regional water demands for electricity generation to 2095. Adv. Water Resour. 52, 296-313.

FAO, 2014. AQUASTAT database. http://www.fao.org/nr/aquastat (accessed 09.06.16)

Feeley III, T.J., Skone, T.J., Stiegel Jr., G.J.et al., 2008. Water: A critical resource in the thermoelectric power industry. Energy 33, 1-11.

Fricko, O., Parkinson, S.C., Johnson, N., et al., 2016. Energy sector water use implications of a 2 ${ }^{\circ} \mathrm{C}$ climate policy. Environ. Res. Lett 11, 034011. 
Hanasaki, N., Fujimori, S., Yamamoto, T., et al., 2013. A global water scarcity assessment under Shared Socio-economic Pathways - Part 1: Water use. Hydrol. Earth Syst. Sci. 17, 23752391.

Hejazi, M., Edmonds, J., Clarke, L., et al., 2014. Long-term global water projections using six socioeconomic scenarios in an integrated assessment modeling framework. Technol. Forecast. Soc. Change 81, 205-226.

Jägermeyr, J., Gerten, D., Heinke, J., et al., 2015. Water savings potentials of irrigation systems: global simulation of processes and linkages. Hydrol. Earth Syst. Sci. 19, 3073-3091.

KC, S., Lutz, W., 2014. The human core of the shared socioeconomic pathways: Population scenarios by age, sex and level of education for all countries to 2100. Glob. Environ. Change. doi:10.1016/j.gloenvcha.2014.06.004

Kua, H.W., Gunawansa, A. 2010. A multi-scale analysis of possible conflicts between climate change mitigation and adaptation initiatives in the building industry and human settlement. Progr Ind Ecol 7, 219-238.

Kua, H.W. 2007. Information flow and its significance in coherently integrated policymaking for promoting energy efficiency. Environ Sci Technol 41, 3047-3054.

Kenny, J.F., Barber, N.L., Hutson. S.S., et al., 2009. Estimated Use of Water in the United States in 2005. U.S. Geological Survey, Reston, Virginia

Klein, D., Luderer, G., Kriegler, E., et al., 2014. The value of bioenergy in low stabilization scenarios: an assessment using REMIND-MAgPIE. Clim. Change 123, 705-718.

Krey, V., Luderer, G., Clarke, L., et al., 2014. Getting from here to there - energy technology transformation pathways in the EMF27 scenarios. Clim Change 123, 369-382.

Kriegler, E., Bauer, N., Popp, A., et al., 2016. Fossil-fueled development (SSP5): an energy and resource intensive scenario for the $21^{\text {st }}$ century. Global Environmental Change.

Kriegler, E., Edmonds, J., Hallegatte, S., et al., 2014. A new scenario framework for climate change research: the concept of shared climate policy assumptions. Clim. Change 122, 401-414.

Kyle, P., Davies, E.G.R., Dooley, J.J., et al., 2013. Influence of climate change mitigation technology on global demands of water for electricity generation. Int. J. Greenh. Gas Control 13, 112-123.

Luderer, G., Krey, V., Calvin, K., et al. 2014. The role of renewable energy in climate stabilization: results from the EMF27 scenarios. Clim. Change 123, 427-441.

Luderer, G., Pietzcker, R.C., Bertram, C., et al., 2013. Economic mitigation challenges: how further delay closes the door for achieving climate targets. Environ. Res. Lett. 8, 34033.

Macknick, J., Newmark, R., Heath, G., et al., 2011. A Review of Operational Water Consumption and Withdrawal Factors for Electricity Generating Technologies. (No. NREL/TP-6A2050900). National Renewable Energy Laboratory, Golden, Colorado.

Meinshausen, M., Raper, S.C.B., Wigley, T.M.L., 2011. Emulating coupled atmosphere-ocean and carbon cycle models with a simpler model, MAGICC6 - Part 1: Model description and calibration. Atmos Chem Phys 11, 1417-1456.

Mouratiadou I., Luderer G., Bauer N., et al., 2016. Emissions and their drivers: sensitivity to economic growth and fossil fuel availability across world regions. Clim. Change 136, 23 37.

O’Neill, B.C., Kriegler, E., Ebi, K.L., et al., 2015. The roads ahead: Narratives for shared socioeconomic pathways describing world futures in the 21 st century. Glob. Environ. Change. doi:10.1016/j.gloenvcha.2015.01.004

O’Neill, B., Kriegler, E., Riahi, et al., 2014. A new scenario framework for climate change research: the concept of shared socioeconomic pathways. Clim. Change 122, 387-400. 
Popp, A., Rose, S., Calvin, K., et al., 2014a. Land-use transition for bioenergy and climate stabilization: model comparison of drivers, impacts and interactions with other land use based mitigation options. Clim. Change 123, 495-509.

Popp, A., Humpenoder, F., Weindl, I., et al., 2014b. Land-use protection for climate change mitigation. Nat. Clim Change 4, 1095-1098.

Popp, A., Dietrich, J.P., Lotze-Campen, H., et al., 2011. The economic potential of bioenergy for climate change mitigation with special attention given to implications for the land system. Environ. Res. Lett. 6, 34017.

Rose, S., Kriegler, E., Bibas, R., et al. 2014. Bioenergy in energy transformation and climate management. Clim. Change 123, 477-493.

Rost, S., Gerten, D., Bondeau, A., et al. 2008. Agricultural green and blue water consumption and its influence on the global water system. Water Resour. Res. 44, W09405.

Shiklomanov, I.A., 2000. Appraisal and Assessment of World Water Resources. Water Int. 25, $11-32$.

Siebert, S., Döll, P., Feick, S., et al., 2007. Global Map of Irrigation Areas version 4.0.1. Johann Wolfgang Goethe Univ. Frankf. Am Main Ger. Food Agric. Organ. U. N. Rome Italy.

UN, 2015. World Population Prospects: The 2015 Revision, Key Findings and Advance Tables. (No. Working Paper No. ESA/P/WP.241.). United Nations, Department of Economic and Social Affairs, Population Division.

van Vuuren, D., Edmonds, J., Kainuma, M., et al., 2011. The representative concentration pathways: an overview. Clim. Change 109, 5-31.

van Vuuren, D., Kriegler, E., O’Neill, B., et al., 2014. A new scenario framework for Climate Change Research: scenario matrix architecture. Clim. Change 122, 373-386.

Williams, J.H., DeBenedictis, A., Ghanadan, R., et al., 2012. The Technology Path to Deep Greenhouse Gas Emissions Cuts by 2050: The Pivotal Role of Electricity. Science 335, 53-59. 


\section{Vitae}

Ioanna Mouratiadou is a researcher at the Potsdam Institute for Climate Impact Research, within the research domain Sustainable Solutions. Her main research interests include the assessment of climate change mitigation scenarios and the study of the interplay between energy, land use and water resource systems. She holds a PhD in Resource and Agricultural Economics.

Anne Biewald is a postdoctoral researcher within the research domain Climate Impacts \& Vulnerabilities at the Potsdam Institute for Climate Impact Research. Her research interests lie in international trade of agricultural goods, water management issues, virtual water, sustainable intensification, poverty issues and economics of adaptation. She has studied landscape ecology and holds a $\mathrm{PhD}$ in economics.

Michaja Pehl is a PhD student at the Potsdam Institute for Climate Impact Research. His work in the Global Energy System Modelling Group of Research Domain III - Sustainable Solutions focuses on the implications of industrial energy and material flows on climate change.

Markus Bonsch is a physicist who, during his $\mathrm{PhD}$ studies at the Potsdam Institute for Climate Impact Research, worked on the field of land use modelling with a special focus on water availability and the representation of the water sector in land use models.

Lavinia Baumstark is a researcher in the Research Domain Sustainable Solutions at the Potsdam Institute for Climate Impact Research. She is member of the Model Operations group focusing on medium and long term model development and efficiency improvements of large-scale models.

David Klein is a researcher at Research Domain III - Sustainable Solutions of the Potsdam Institute for Climate Impact Research. His research focuses on the assessment of land-based mitigation options, in particular the deployment of bioenergy for climate change mitigation. His recent work has examined the global economic long-term potential of modern biomass.

Alexander Popp is a senior researcher at the Potsdam Institute for Climate Impact Research and head of the working group on land use management. His scientific work concentrates on the interplay between global change, agriculture and food production, land and water use, and various climate change adaptation and mitigation options.

Gunnar Luderer is a senior researcher at the Potsdam Institute for Climate Impact Research. He is head of the Global Energy Systems group within Research Domain III - Sustainable Solutions and works on sustainable climate change mitigation strategies.

EImar Kriegler is senior researcher and deputy chair of the Research Domain Sustainable Solutions at the Potsdam Institute for Climate Impact Research, Germany. His principal research focuses on the integrated assessment of climate change and scenario development. 


\section{The impact of climate change mitigation on water demand for energy and food: an integrated analysis based on the Shared Socioeconomic Pathways - Supplementary Material}

Ioanna Mouratiadou*a, Anne Biewald ${ }^{\mathrm{a}}$, Michaja Pehl ${ }^{\mathrm{a}}$, Markus Bonsch ${ }^{\mathrm{a}}$, Lavinia Baumstark ${ }^{\mathrm{a}}$, David Klein $^{\mathrm{a}}$, Alexander Popp ${ }^{\mathrm{a}}$, Gunnar Luderer ${ }^{\mathrm{a}}$, Elmar Kriegler ${ }^{\mathrm{a}}$

${ }^{a}$ Potsdam Institute for Climate Impact Research, PO Box 601203, 14412 Potsdam, Germany

* Corresponding author: mouratiadou@pik-potsdam.de; Potsdam Institute for Climate Impact Research, PO Box 6012 03, 14412 Potsdam, Germany; +49 (0) 3312882687

\section{Methodology}

\subsection{The MAgPIE-REMIND coupling}

The MAgPIE-REMIND models are coupled in order to establish equilibrium of bioenergy and emissions markets in an iterative procedure (Bauer et al., 2014). That is, the REMIND model estimates greenhouse gas emission prices and bioenergy demand paths, that are communicated to the MAgPIE model. In turn, MAgPIE computes land use emissions and bioenergy prices which result in an update of the bioenergy supply curve within REMIND. The two models exchange information at the regional level, using a pre-established one-to-one mapping between the regions of the two models. The soft link iterates between the two models until emission and bioenergy markets are in equilibrium. At this point the bioenergy demand patterns computed by REMIND are achieved in MAgPIE at the same emissions and bioenergy prices on which the demand patterns were based on. Additionally, the emissions emerging from pre-defined climate policy scenarios in REMIND take into account emissions from the land use sector derived in MAgPIE under the emissions prices and bioenergy use associated with the same climate policy (Kriegler et al., in press). Once the iterative process is finished, the resulting emission paths of both models are introduced into the MAGICC model (Meinshausen et al., 2011) in order to compute climatic variables.

\subsection{The LPJmL model}

The LPJmL model represents globally biogeochemical land surface processes of vegetation and soils (Rost et al., 2008), simulating daily water and carbon fluxes in direct coupling with the establishment, growth, and productivity of major natural and agricultural plant types. The spatiotemporal distribution of natural vegetation, represented through nine plant functional types, is dynamically simulated based on climatic and carbon dioxide forcing (Sitch et al., 2003). Photosynthesis modeling in LPJmL follows a modified approach by Farquhar et al. (1980). Sowing dates are dynamically calculated based on climatic and crop conditions (Waha et al., 2012).

Thirteen soil types are differentiated, according to their soil texture, water holding capacity, and hydraulic conductivity (Schaphoff et al., 2013). LPJmL includes information on reservoirs, 
affecting the seasonal timing of discharge and the amount of water locally available for irrigation. The locations of the reservoirs are obtained from the GRanD database (Lehner and Döll, 2004). This global database contains geographical locations for approximately 7000 dams, including information on maximum storage capacity. In grid cells where water storage facilities are provided by dams total annual blue water resources are available for irrigation (Biemans et al., 2011). In reality not all return flows are recoverable, due to inaccessibility or degradation, but LPJmL considers only the water outflow to oceans as non-recoverable (Jägermeyr et al., 2015). In Biemans et al. (2009), LPJmL results have been systematically validated against discharge observations for 300 globally distributed river basins.

\subsection{The MAgPIE model}

MAgPIE (Model of Agricultural Production and its Impact on the Environment) is a global, spatially explicit, economic land-use model solving in a recursive-dynamic mode in ten-year time steps (Lotze-Campen et al., 2008). Spatially explicit land types in MAgPIE comprise cropland, pasture, forest, urban areas, and other land (Krause et al., 2013). MAgPIE distinguishes agricultural demand trajectories for ten world regions and uses a 0.5 degree resolution on the supply side in order to produce the demanded agricultural commodities. Due to computational constraints, all model inputs on the supply side are aggregated to clusters for the optimization process based on a k-means clustering algorithm (Dietrich et al., 2013). Bioenergy demand is prescribed by scenario-specific REMIND demand trajectories. Non-energy agricultural demand is also scenario-specific and changes over time as prescribed exogenously based on the assumed trajectory of regional income per capita.

Bioenergy and non-energy crop production are directly competing for land and other agricultural resources, including water. This competition determines commodity prices, based on the objective to minimize global agricultural production costs while satisfying demands for food and energy and respecting land and water constraints. There is no price response to the exogenously prescribed demands or an underlying 'food-first' policy (Klein et al., 2014). Agricultural production costs include factor costs for labor, capital, and intermediate inputs derived from the GTAP database (Narayanan and Walmsley, 2008), investments into research and development (R\&D), land expansion costs, costs for additional irrigation infrastructure, as well as transport costs. R\&D investments allow region specific crop yield increases. This endogenous implementation of technological change is based on a surrogate measure for agricultural land-use intensity (Dietrich et al., 2014). As clarified by Bonsch et al., (2014), R\&D investments lead to crop yield increases for the same amount of crop water demand per hectare, thus enhancing water productivity per ton. This is in line with findings that improved agronomic practices and yield increases are crucial for improving water productivity (Kijne et al., 2003; Molden et al., 2010; Rosegrant et al., 2009). Except R\&D investments, increase in agricultural production can also be achieved via land expansion (Klein et al., 2014), reallocation of production into areas of higher productivity, or expansion of the irrigated area. At a regional level, yields in 1995 are calibrated to meet historical Food and Agriculture Organization (FAOSTAT, 2013) cropland estimates (Bonsch et al., 2015).

Information on water requirements and water availability are provided by the LPJmL model on a yearly basis. In order to simulate the seasonal distribution of water, a process based estimate of the 
reduction of annual available water for irrigation due to seasonal variation is implemented, where irrigation water can only be used by plants during their growing period (Bonsch et al., 2015). A comparison of base year agricultural water withdrawals to historic data from various sources shows a good fit of our results to observed data (SM Figure 1) and therefore no additional model calibration is performed. An extensive description of water dynamics in MAgPIE can also be found in Bonsch et al. (2015, 2014).

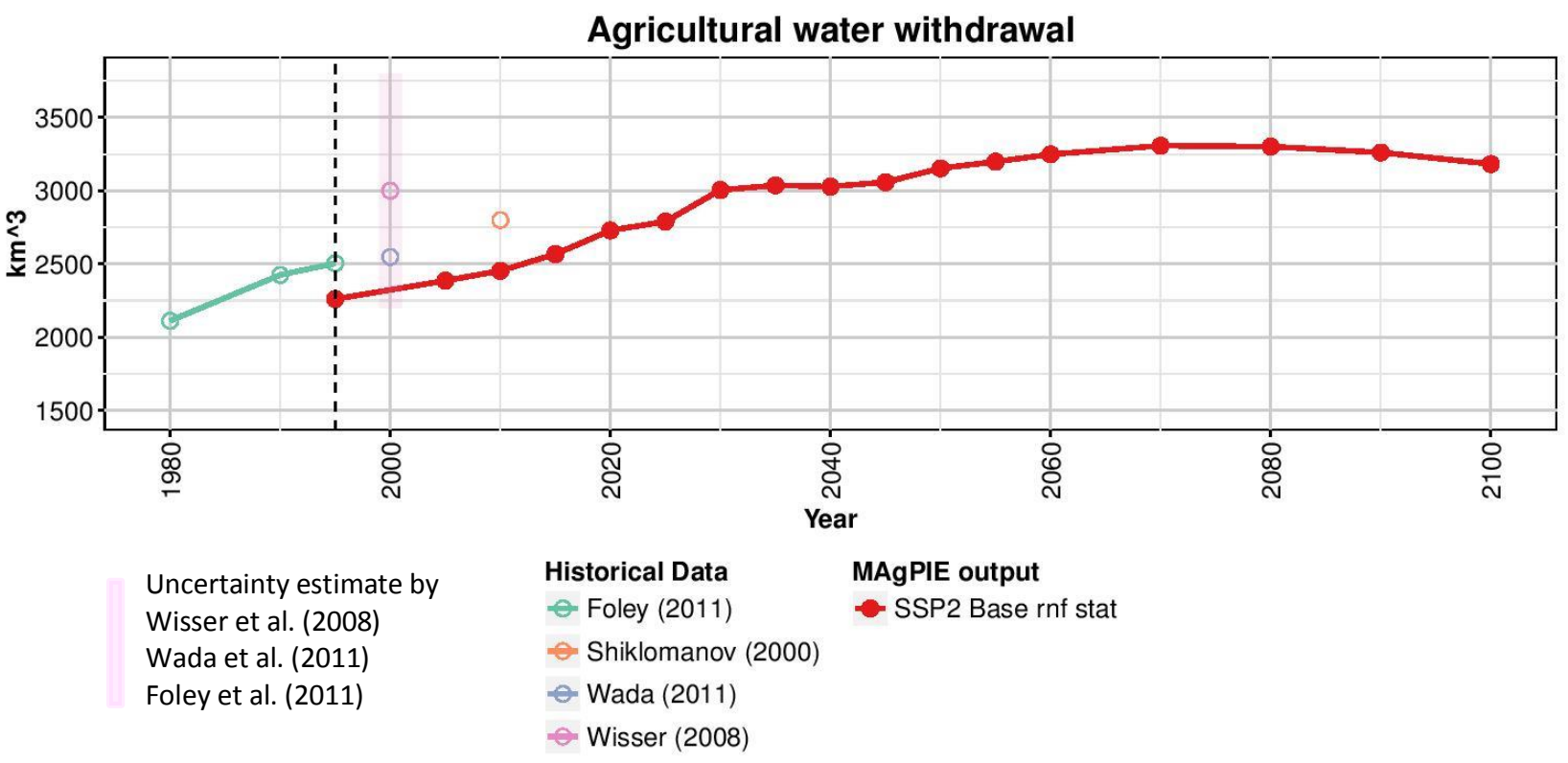

SM Figure 1: Comparison of MAgPIE results on agricultural water withdrawals to historic data.

\subsection{The REMIND model}

REMIND (Regional Model of Investments and Development) is a global multi-regional energyeconomy-climate model spanning the years 2005-2100 (Luderer et al., 2015). The macroeconomic core of REMIND is a growth model based on the theoretical framework established by Ramsey (1928) to describe optimal trade-offs between investments into productive capital (e.g. factories and machinery) and consumable goods. REMIND considers 11 world regions and explicitly represents trade in primary energy carriers and final goods. The macro-economic production input factors are capital, labor and energy. The macro-economic core and the energy system module are hard-linked via the costs incurred by the energy system and final energy demand. Economic activity results in demand for final energy such as electricity, non-electric energy for the stationary end-uses, and transport energy (Luderer et al., 2015; Mouratiadou et al., 2015).

The energy system of REMIND represents more than 50 technology types for the conversion of primary energy carriers (e.g. coal, gas, or incident solar energy) to secondary energy carriers (such as electricity, liquid fuels or gases) as well as the provision of final energy and energy services (e.g. passenger or freight transportation). REMIND represents technological change in crucial innovative technologies, such as solar photovoltaics, wind energy and electric vehicles explicitly. It also accounts for direct greenhouse gases emissions from the energy sector as well as indirect 
emissions related to fossil resource extraction and bioenergy production, thus enabling an integrated analysis of climate change mitigation strategies. The model accounts for the integration challenges related to intermittent variable renewable electricity supply (solar and wind power) in terms of additional expenses for expansion of transmission grids and investments into electricity storage technologies (Pietzcker et al., 2014). In the present model version, the impact of variable electricity supply from wind and solar on the scheduling of hydropower is not represented.

The endogenous features of the REMIND model affecting directly water use include electricity demand, the electricity mix, vintage structure, and excess heat. Electricity is produced from exhaustible or renewable primary energy carriers, where the former exhibit extraction costs increasing with cumulated extraction. The capacities needed for energy transformations are subject to investment, as well as operation and maintenance costs. Wind and solar technologies feature learning-by-doing which decreases investment costs.

REMIND tracks the age structure of power plants by representing capital vintages for each time step, and different technical lifetime of technologies. To represent the age structure realistically, fixed vintage factors are applied that imply low depreciation rates for younger cohorts, and high depreciation for vintages close to the end of their technical life-times. The information on vintage age structure is used to estimate the share of individual vintages (Vin) build in time step $t b$ and still in use in time step $t$ and region $r$.

Excess heat of thermoelectric power generation (Heat) for conventional thermal power technologies elt (including fossil, biomass and nuclear-fueled technologies) is estimated as the difference between fuel input (Fuel) minus electricity production (fuel input times efficiency $\eta_{t, r, e l}$ ) and smokestack losses $(s l$ ) (assumed to be $10 \%$ of fuel inputs for non-nuclear thermoelectric technologies), similarly to Bijl et al., (2016).

$$
\text { Heat }_{r, t, e l t}=\left(1-\eta_{r, t, e l t}-s l\right) \cdot \text { Fuel }_{r, t, e l t}
$$

In the transformation of primary energy into electricity, the time dependent and regionally differentiated thermal efficiencies are taken into account, and therefore influence the estimate of excess heat in time per region and technology. Thermal efficiencies are improving over time and converging between regions, and this reduces excess heat and associated water requirements of thermal power plants over time.

Global water withdrawal and consumption for thermal power technologies $\left(W T_{t}\right)$ are calculated by multiplying the excess heat from thermal power plants with the share of technology vintages (Vin), the vintage-specific share $(c s h)$ of different cooling technologies $(c l)$, and the cooling technology specific water withdrawal or consumption coefficient for excess heat (cheat) and summing over regions, technologies and vintages.

$$
W T_{t}=\sum_{r, e l t, t b}\left(\operatorname{Vin}_{r, t, e l t, t b} \cdot H_{e a t} t_{r, t, e l t} \cdot \sum_{c l}\left(c s h_{r, e l t, t b, c l} \cdot c_{\text {cheat }} \text { elt,cl}\right)\right)
$$


Global water withdrawal and consumption for non-biomass renewable technologies $\operatorname{elr}\left(W R_{t}\right)$ are estimated in a similar manner, only that they are based on electricity output $(E l)$ and electricity output-based coefficients instead of excess heat.

$$
W R_{t}=\sum_{r, e l r, t b}\left(\operatorname{Vin}_{r, t, e l r, t b} \cdot E l_{r, t, e l r} \cdot \sum_{c l}\left(c s h_{r, e l r, t b, c l} \cdot c e l_{e l r, c l}\right)\right)
$$

The shares $(c s h)$ of cooling technologies $(c l)$, and the water withdrawal and consumption coefficients ( $\mathrm{cel}$ ) are exogenous. Water withdrawal and consumption coefficients per electricity output are based on Macknick et al. $(2012,2011)$ and shown for the REMIND technologies in SM Table 1. These coefficients have been utilized by numerous studies in the literature analyzing water demand for electricity generation (e.g. Byers et al., 2014; Davies et al., 2013). The electricity output-based coefficients from Macknick et al. $(2012,2011)$ are static in time and have been converted into the coefficients for excess heat for the thermal power plant technologies (cheat) by back calculating the respective value for the US for 2005. Assuming that the cooling efficiency of a technology per unit of excess heat is constant across regions and time, the estimated value is then applied to all regions and time steps. The shares of cooling technologies per electricity technology are deduced from (Kyle et al., 2013).

Various processes and parameters represented in REMIND are calibrated to historic data in order to match base year observations or historic patterns. In 2005, primary energy and final energy demand are calibrated to the International Energy Agency energy balance sheets (IEA 2007a, 2007b) and greenhouse gas emissions to the Emission Database for Global Atmospheric Research (EDGAR 2011). The future evolution of labor productivity and energy efficiency improvements are calibrated to reproduce historic patterns (Luderer et al., 2015). In this exercise, labor productivity improvements were adjusted to reproduce the gross domestic product (GDP) projections of the SSP baseline cases using the projections of the Organization for Economic Cooperation and Development (Dellink et al., in press).

The combination of the calibrated baseyear data on electricity final energy demand with the water withdrawal and consumption coefficients from Macknick et al. (2012, 2011) and the cooling shares from (Kyle et al., 2013), result in a good fit of our water demand baseyear values (496 $\mathrm{km}^{3} /$ year for withdrawal, $26 \mathrm{~km}^{3} /$ year for consumption excluding hydropower, and 50 for hydropower consumption, Figure 2) to the values reported in the literature. Regarding water withdrawal, recent studies using 2005 as their baseyear include Bijl et al. (2016) which reports about $500 \mathrm{~km}^{3} /$ year and Hejazi et al. (2014) reporting $535 \mathrm{~km}^{3} /$ year. Older studies include Davies et al. (2013) and Kyle et al. (2013) reporting about $570 \mathrm{~km}^{3} / y$ ear for 2005, (OECD 2012) with about 570 for $2000 \mathrm{~km}^{3} /$ year, and Vassolo and Döll (2005) reporting about $400 \mathrm{~km}^{3} /$ year for 1995. Further, Davies et al. (2013) provide information of literature estimates of cooling water from different sources, with a global total (using values from 1995, 2000, or 2005 depending on availability) of about $500 \mathrm{~km}^{3} /$ year. Regarding water consumption, Bijl et al. (2016) reports an about $25 \mathrm{~km}^{3} /$ year (excluding hydropower) and Hejazi et al. (2014) and Davies et al. (2013) about $76 \mathrm{~km}^{3} /$ year for all uses. 
SM Table 1: Water withdrawal and water consumption coefficients for electricity output

\begin{tabular}{|c|c|c|c|}
\hline $\begin{array}{l}\text { Electricity Production } \\
\text { Technology }\end{array}$ & $\begin{array}{l}\text { Cooling } \\
\text { Technology }^{6}\end{array}$ & $\begin{array}{l}\text { Water Withdrawal } \\
\text { (m3/MWh) }\end{array}$ & $\begin{array}{l}\text { Water Consumption } \\
(\mathrm{m} 3 / \mathrm{MWh})\end{array}$ \\
\hline pulverized coal & wet tower & 3.8 & 2.6 \\
\hline pulverized coal & once through & 137.6 & 0.95 \\
\hline pulverized coal & cooling pond & 46.28 & 2.06 \\
\hline pulverized coal with ccs & wet tower & 4.25 & 3.2 \\
\hline pulverized coal with ccs & once through & 153.76 & 1.17 \\
\hline pulverized coal with ccs & cooling pond & 51.71 & 2.54 \\
\hline igcc (coal in combined cycle) & wet tower & 1.48 & 1.41 \\
\hline igcc & once through & 53.4 & 0.51 \\
\hline igcc & cooling pond & 17.96 & 1.12 \\
\hline igcc with ccs & wet tower & 2.22 & 2.04 \\
\hline igcc with ces & once through & 80.23 & 0.74 \\
\hline igcc with ces & cooling pond & 26.98 & 1.62 \\
\hline coal chp (combined heat and power) & wet tower & 1.9 & 1.3 \\
\hline coal chp & once through & 68.8 & 0.47 \\
\hline coal chp & cooling pond & 23.14 & 1.03 \\
\hline natural gas turbine & wet tower & 0 & 0 \\
\hline natural gas turbine & once through & 0 & 0 \\
\hline natural gas turbine & cooling pond & 0 & 0 \\
\hline ngcc (natural gas in combined cycle) & wet tower & 2.18 & 1.56 \\
\hline ngec & once through & 73.48 & 0.56 \\
\hline ngec & cooling pond & 16.41 & 1.66 \\
\hline ngcc with ccs & wet tower & 1.88 & 1.43 \\
\hline ngcc with ccs & once through & 84.45 & 0.72 \\
\hline ngcc with ccs & cooling pond & 44.16 & 1.73 \\
\hline gas chp & wet tower & 2.28 & 1.56 \\
\hline gas chp & once through & 66.25 & 0.45 \\
\hline gas chp & cooling pond & 2.28 & 1.56 \\
\hline oil & wet tower & 4.55 & 3.13 \\
\hline oil & once through & 132.49 & 0.91 \\
\hline oil & cooling pond & 4.55 & 3.13 \\
\hline
\end{tabular}

${ }^{6}$ The dry and sea water cooling types for most technologies assume no withdrawal or consumption of freshwater. 


\begin{tabular}{|l|l|r|r|}
\hline nuclear & wet tower & 4.17 & 2.54 \\
\hline nuclear & once through & 167.88 & 1.02 \\
\hline Nuclear & cooling pond & 26.69 & 2.31 \\
\hline biomass chp & wet tower & 1.9 & 1.3 \\
\hline biomass chp & once through & 68.8 & 0.47 \\
\hline biomass chp & cooling pond & 23.14 & 1.03 \\
\hline bioigcc (biomass in combined cycle) & wet tower & 1.48 & 1.41 \\
\hline Bioigcc & once through & 53.4 & 0.51 \\
\hline Bioigcc & cooling pond & 17.96 & 1.12 \\
\hline bioigcc with ccs & wet tower & 2.22 & 2.04 \\
\hline bioigcc with ccs & once through & 80.23 & 0.74 \\
\hline bioigcc with ccs & cooling pond & 26.98 & 1.62 \\
\hline Geothermal & wet tower & 18.11 & 18.11 \\
\hline Geothermal & cooling pond & 5.32 & 5.32 \\
\hline Geothermal & Dry & 3.22 & 3.22 \\
\hline Hydropower & - & 0 & 17 \\
\hline Wind & - & 0 & 0 \\
\hline solar photovoltaics & - & 0.1 & 0.1 \\
\hline CSP (concentrated solar power) & wet tower & 3.27 & 3.27 \\
\hline CSP & cooling pond & 1.28 & 1.28 \\
\hline CSP & Dry & 0.3 & 0.3 \\
\hline
\end{tabular}

\subsection{Water Use Indicators}

Electricity water requirements can vary considerably depending on the electricity and cooling technology that is employed, but also the water use indicator that is explored. The analysis of the water withdrawal indicator highlights more prominently shifts in the use of thermal power technologies and once-through cooling, since water withdrawals are noticeably higher for these technologies (see SM Table 1 for water withdrawal and water consumption coefficients). Water consumption is significantly lower than water withdrawal for thermoelectric cooling technologies, but the two indicators are equal for non-biomass renewable electricity sources (Macknick et al., 2011). Also, the water consumption of some non-biomass renewables is in the same order of magnitude (e.g. Concentrated Solar power (CSP)) or higher (e.g. hydropower or geothermal power) than this of conventional thermoelectric power plants. Therefore, changes associated to non-biomass renewable technologies show up mainly through changes in the water consumption indicator. Further, a shift away from once-through towards recirculating technologies will most likely decrease water withdrawals but increase water consumption, since the water consumption of recirculating systems is typically higher than this of once-through systems.

Further, the impacts on the water environment encapsulated by each of the two indicators differ. The water withdrawal indicator reflects better water quality issues, since part of the water is turned into water systems at high temperatures potentially resulting in thermal water pollution. Also, since it is associated to large amounts of water, it can highlight more noticeably water 
scarcity risks associated to the security of electricity supply. The water consumption indicator reflects water that is not directly returned into the water systems, and can have impacts in cases with low water availability (Macknick et al., 2012).

\subsection{Scenarios and application of Shared Socio-economic Pathways}

A brief characterization of the three SSPs investigated in our analysis is provided below, using excerpts of the narrative descriptions by O'Neill et al. (2015):

a) SSP1: Sustainability - Taking the green road (low challenges to mitigation):

"The world shifts gradually, but pervasively, toward a more sustainable path, emphasizing more inclusive development that respects perceived environmental boundaries..."

b) SSP2: Middle of the Road (moderate challenges to mitigation):

"The world follows a path in which social, economic, and technological trends do not shift markedly from historical patterns..."

c) SSP5: Fossil-fueled development - Taking the highway (high challenges to mitigation):

"Driven by the economic success of industrialized and emerging economies, this world places increasing faith in competitive markets, innovation and participatory societies to produce rapid technological progress and development of human capital as the path to sustainable development....the push for economic and social development is coupled with the exploitation of abundant fossil fuel resources and the adoption of resource and energy intensive lifestyles around the world."

In order to increase consistency with the SSPs implementation in the REMIND-MAgPIE framework, we do not take into account feedbacks of the climate system. Climate change may result in important impacts on crop yields and water availability. Also it can affect the operation of water cooled thermoelectric power generation via changed hydrological variability and higher temperatures that reduce the thermal efficiency and cooling of power stations and result in higher emissions intensity of electricity generation (Byers et al., 2014; van Vliet et al., 2012; Förster and Lilliestam, 2010). Considering such effects would allow exploring the possibility of climate change induced water bottlenecks in agricultural or electricity production. Although such feedbacks can be important, by design the consideration of climate change impacts are not part of the default SSPs specification (Bauer et al., submitted), and they are not included here.

Further, in this application, as in the SSPs application of the REMIND-MAgPIE models, it is assumed that half of total available water is reserved for non-agricultural water uses including domestic, industrial, and environmental purposes, while irrigated agriculture can use the remaining half. The sensitivity of our results in relation to this assumption is explored via a sensitivity analysis. 
SM Table 2: Full scenario matrix

\begin{tabular}{|c|c|c|c|c|}
\hline Scenario & $\begin{array}{l}\text { Socio- } \\
\text { economics }\end{array}$ & Climate policy & $\begin{array}{l}\text { Bioenergy } \\
\text { Irrigation }\end{array}$ & Cooling \\
\hline 1. SSP1 Base irr stat & SSP1 & No climate policy & Full & Static \\
\hline 2. SSP2 Base irr stat & SSP2 & No climate policy & Full & Static \\
\hline 3. SSP5 Base irr stat & SSP5 & No climate policy & Full & Static \\
\hline 4. SSP1 Pol irr stat & SSP1 & RCP 2.6 & Full & Static \\
\hline 5. SSP2 Pol irr stat & SSP2 & RCP 2.6 & Full & Static \\
\hline 6. SSP5 POl irr stat & SSP5 & RCP 2.6 & Full & Static \\
\hline 7. SSP1 Base rnf stat & SSP1 & No climate policy & None & Static \\
\hline 8. SSP2 Base rnf stat & SSP2 & No climate policy & None & Static \\
\hline 9. SSP5 Base rnf stat & SSP5 & No climate policy & None & Static \\
\hline 10. SSP1 Pol rnf stat & SSP1 & RCP 2.6 & None & Static \\
\hline 11. SSP2 Pol rnf stat & SSP2 & RCP 2.6 & None & Static \\
\hline 12. SSP5 Pol rnf stat & SSP5 & RCP 2.6 & None & Static \\
\hline 13. SSP1 Base irr dyn & SSP1 & No climate policy & Full & Dynamic \\
\hline 14. SSP2 Base irr dyn & SSP2 & No climate policy & Full & Dynamic \\
\hline 15. SSP5 Base irr dyn & SSP5 & No climate policy & Full & Dynamic \\
\hline 16. SSP1 Pol irr dyn & SSP1 & RCP 2.6 & Full & Dynamic \\
\hline 17. SSP2 Pol irr dyn & SSP2 & RCP 2.6 & Full & Dynamic \\
\hline 18. SSP5 Pol irr dyn & SSP5 & RCP 2.6 & Full & Dynamic \\
\hline 19. SSP1 Base rnf dyn & SSP1 & No climate policy & None & Dynamic \\
\hline 20. SSP2 Base rnf dyn & SSP2 & No climate policy & None & Dynamic \\
\hline 21. SSP5 Base rnf dyn & SSP5 & No climate policy & None & Dynamic \\
\hline 22. SSP1 Pol rnf dyn & SSP1 & RCP 2.6 & None & Dynamic \\
\hline 23. SSP2 Pol rnf dyn & SSP2 & RCP 2.6 & None & Dynamic \\
\hline 24. SSP5 Pol rnf dyn & SSP5 & RCP 2.6 & None & Dynamic \\
\hline
\end{tabular}




\section{Additional Figures}

\subsection{Effects of climate change mitigation on water demand}
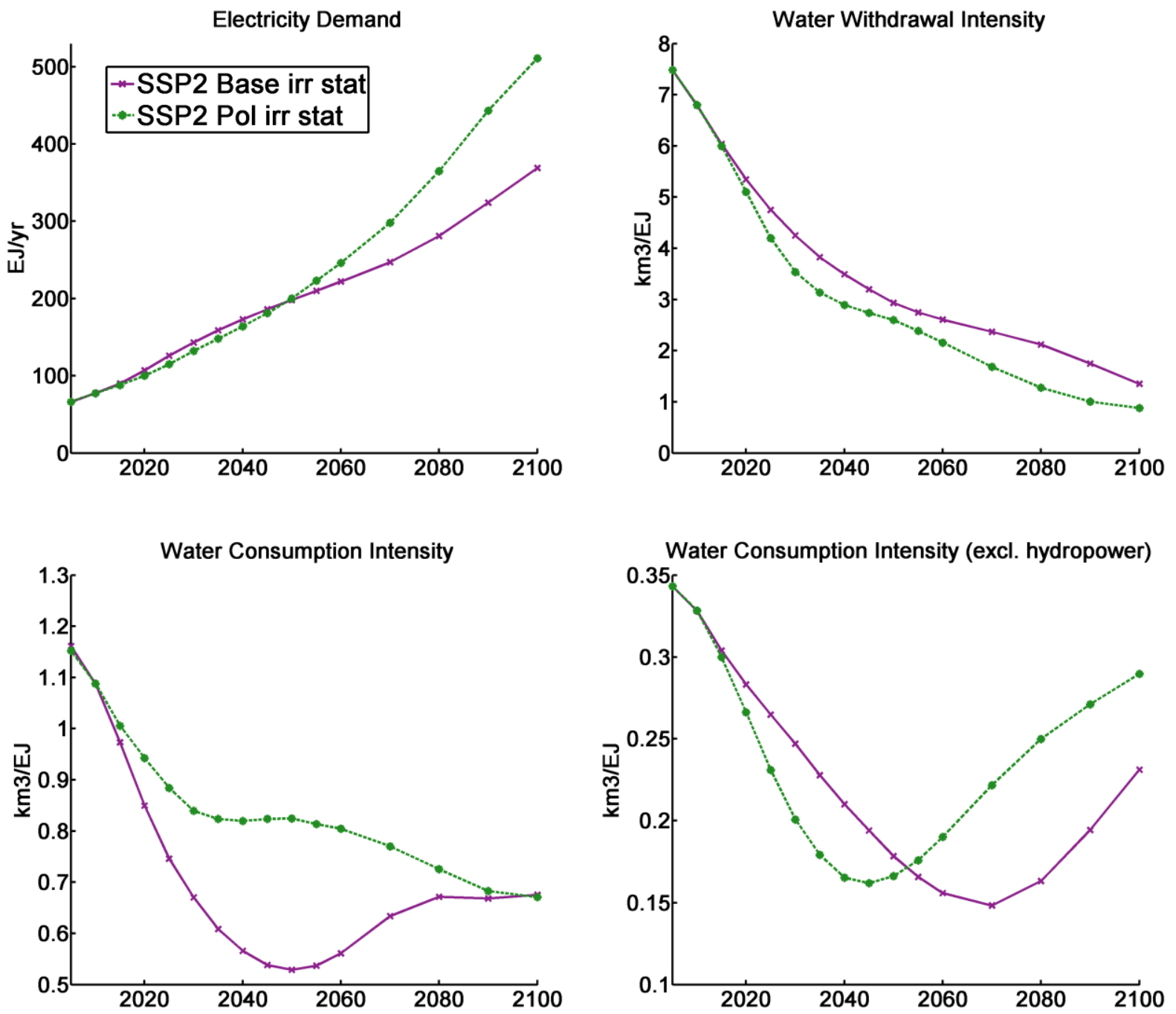

SM Figure 2: Electricity water demand drivers for the SSP2 Baseline and Policy scenarios. 
Water Consumption - SSP2 Base irr stat

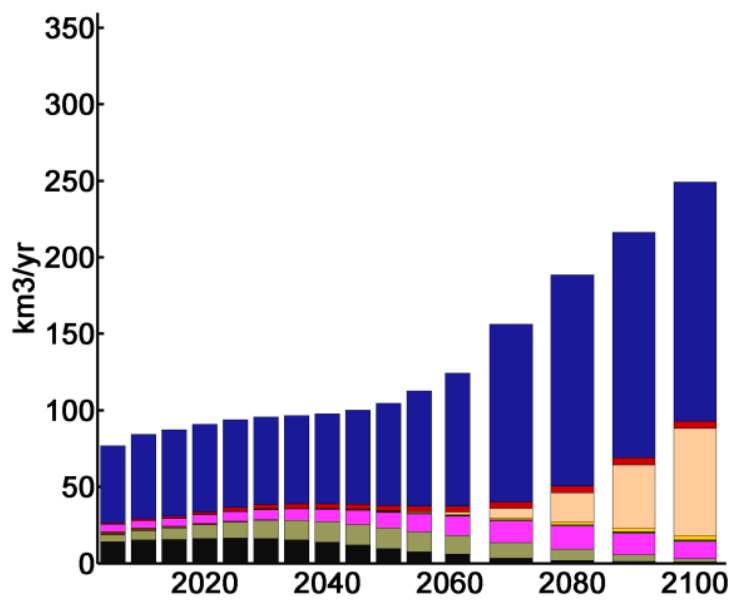

Water Consumption - SSP2 Pol irr stat

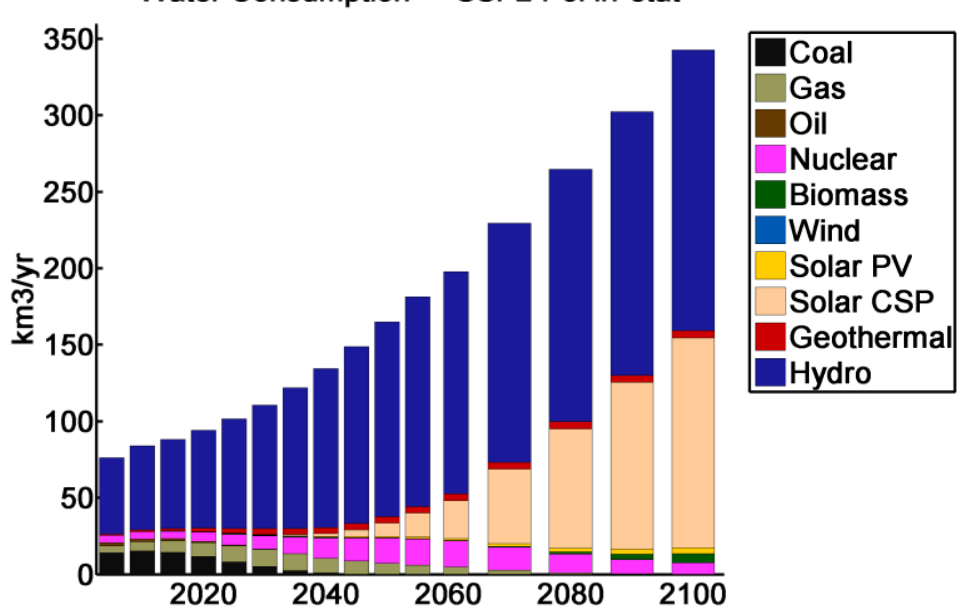

SM Figure 3: Decomposition of water demand per technology for the SSP2 Baseline and Policy scenarios. 


\subsection{Effects of future socioeconomic pathways}
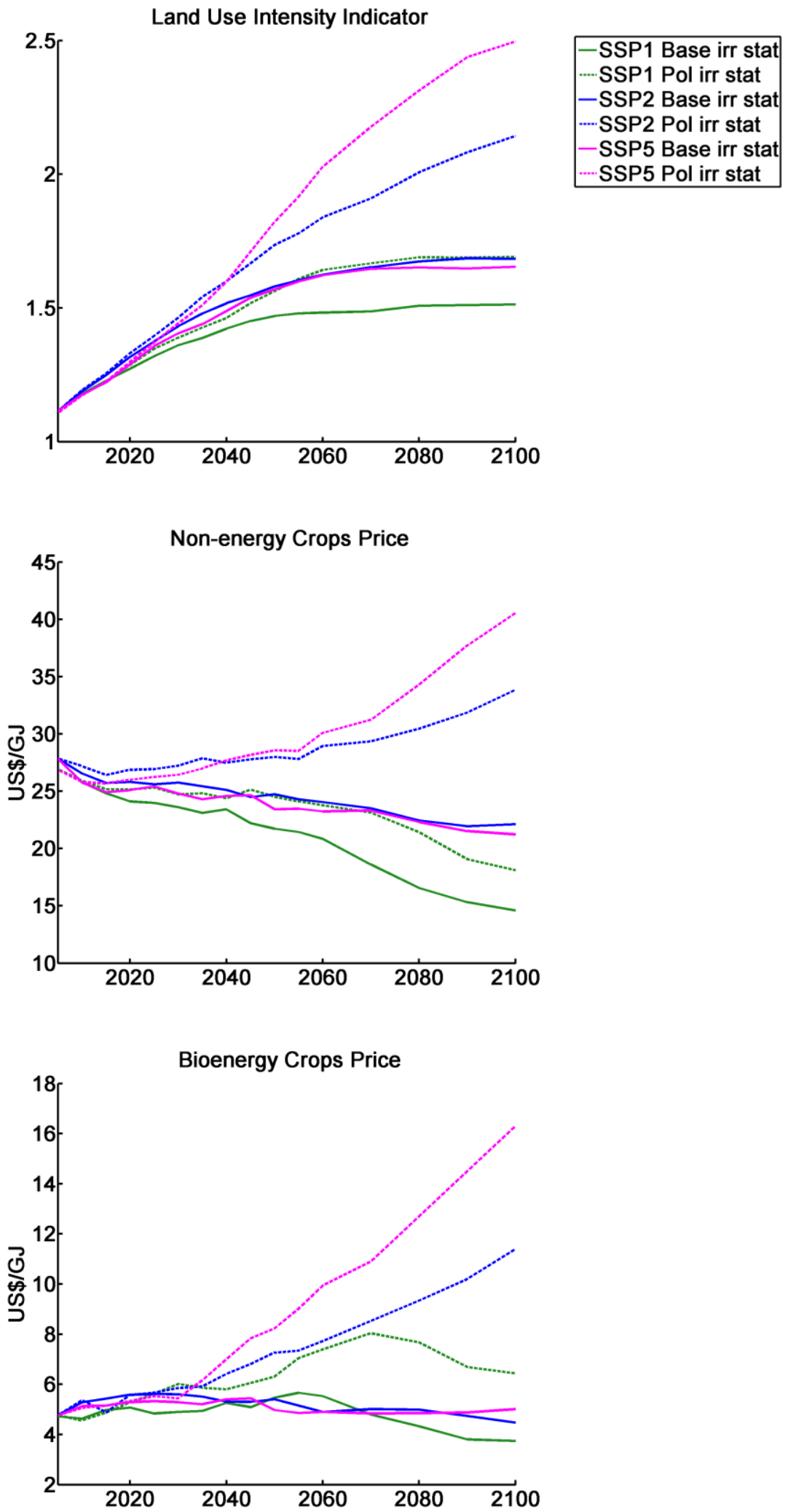

SM Figure 4: Land use intensity, and non-energy and bioenergy crop prices for the Baseline and Policy scenarios across SSPs. 
Cumulated Water Use (2005-2100)

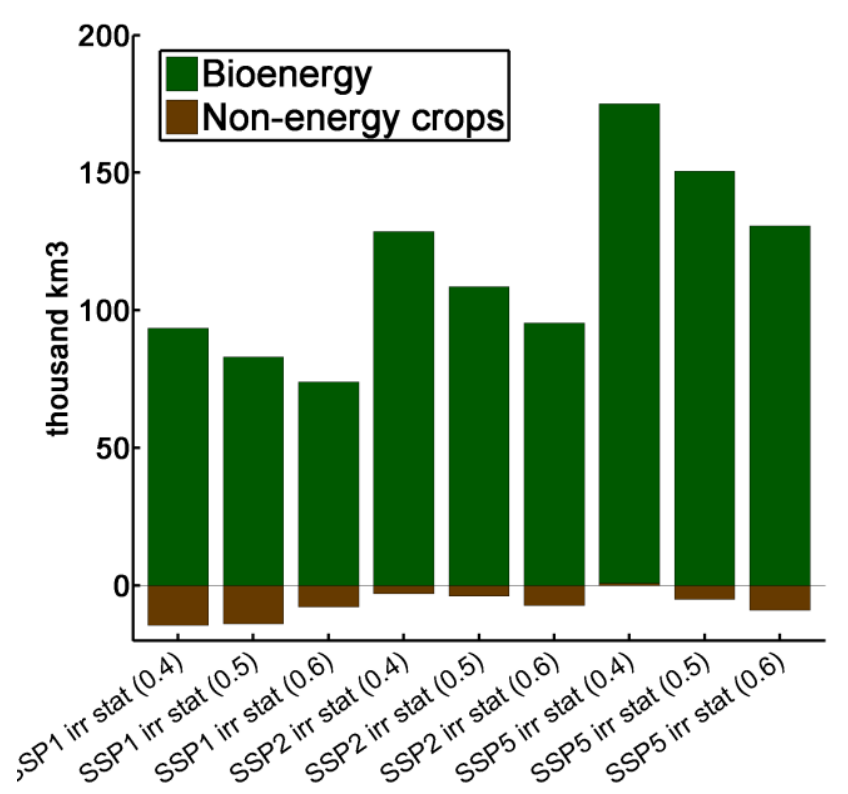

SM Figure 5: Differences in cumulated water withdrawals between the Baseline and Policy scenarios across SSPs, and across assumptions on the fraction of water reserved for non-agricultural purposes. Negative numbers indicate lower values in the Policy scenarios compared to the equivalent Baseline scenarios. 

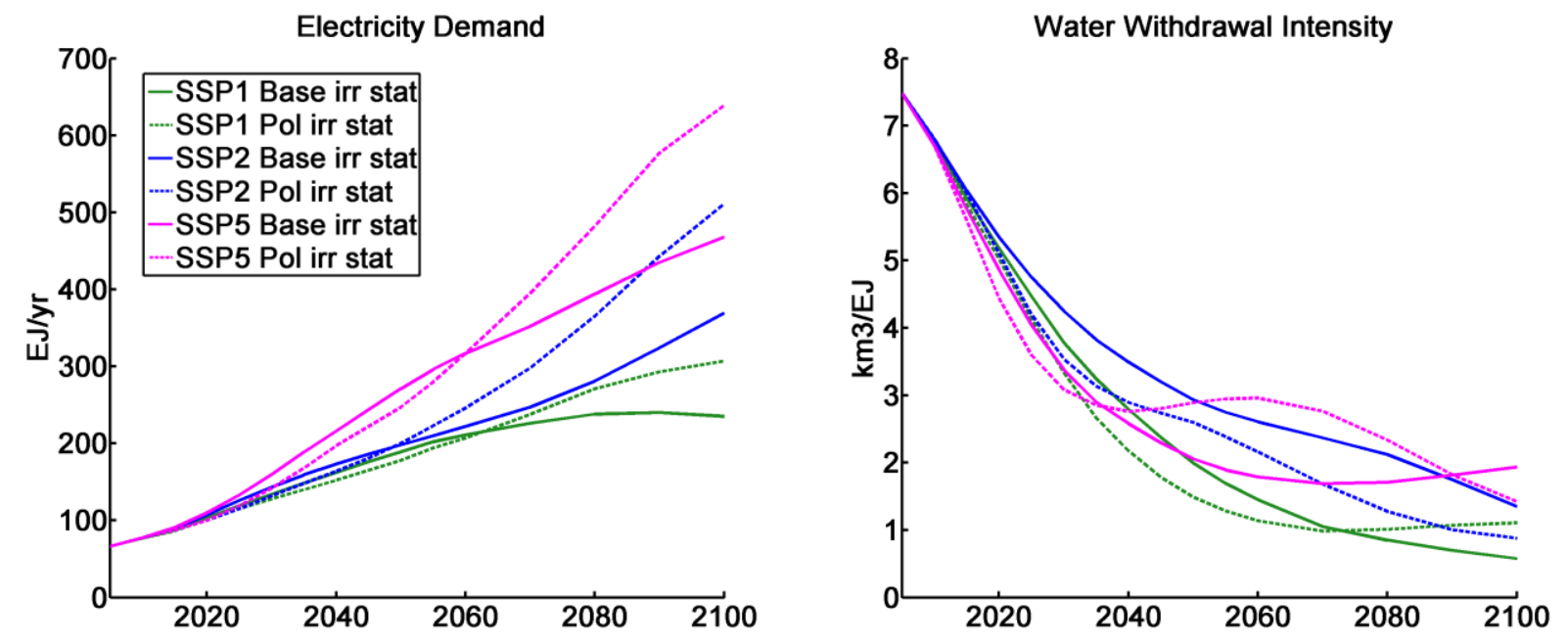

SM Figure 6: Electricity water demand drivers for the Baseline and Policy scenarios across SSPs. 

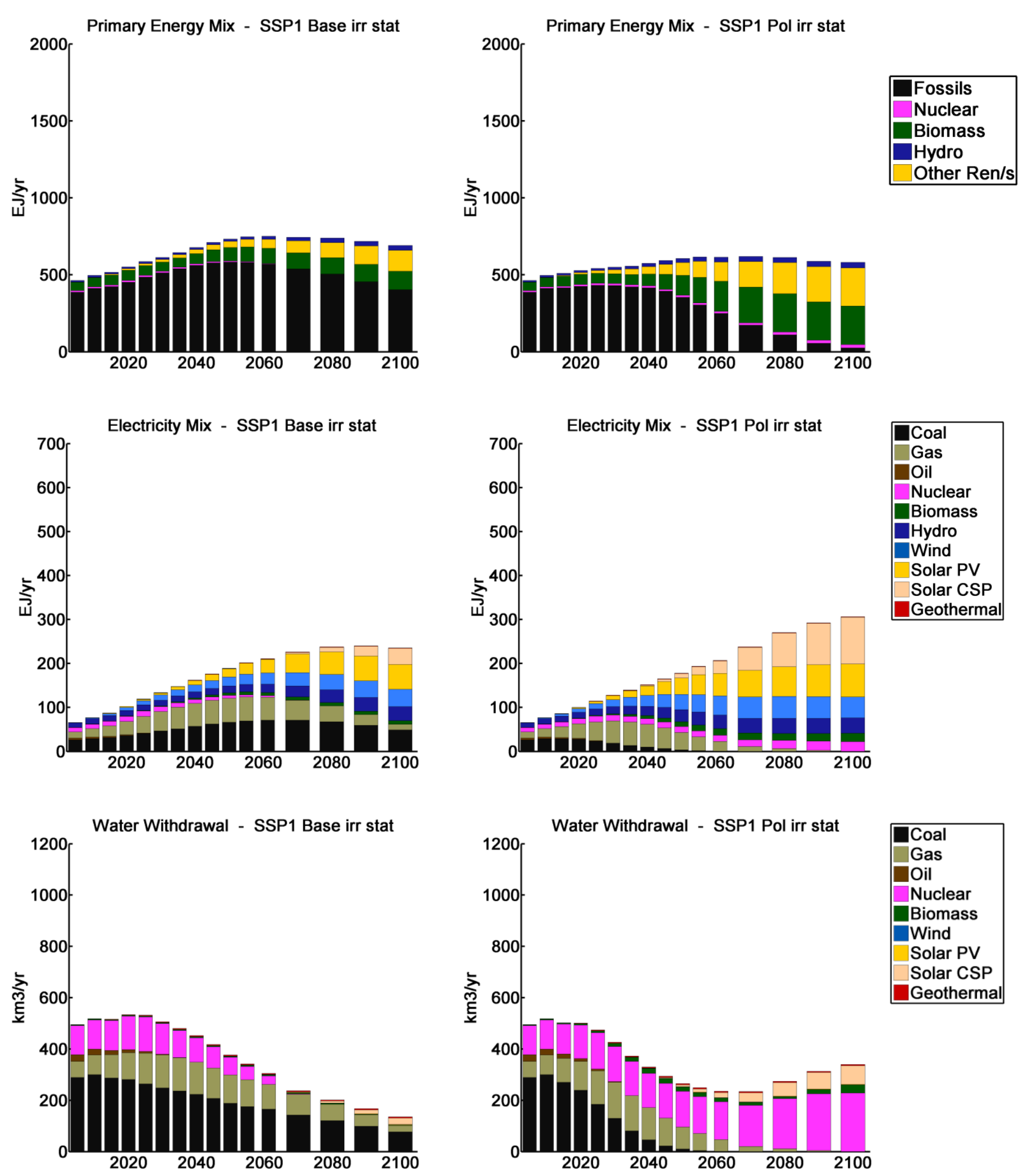

SM Figure 7: Primary energy, electricity, and electricity water withdrawal mixes for the SSP1 Baseline and Policy scenarios. 

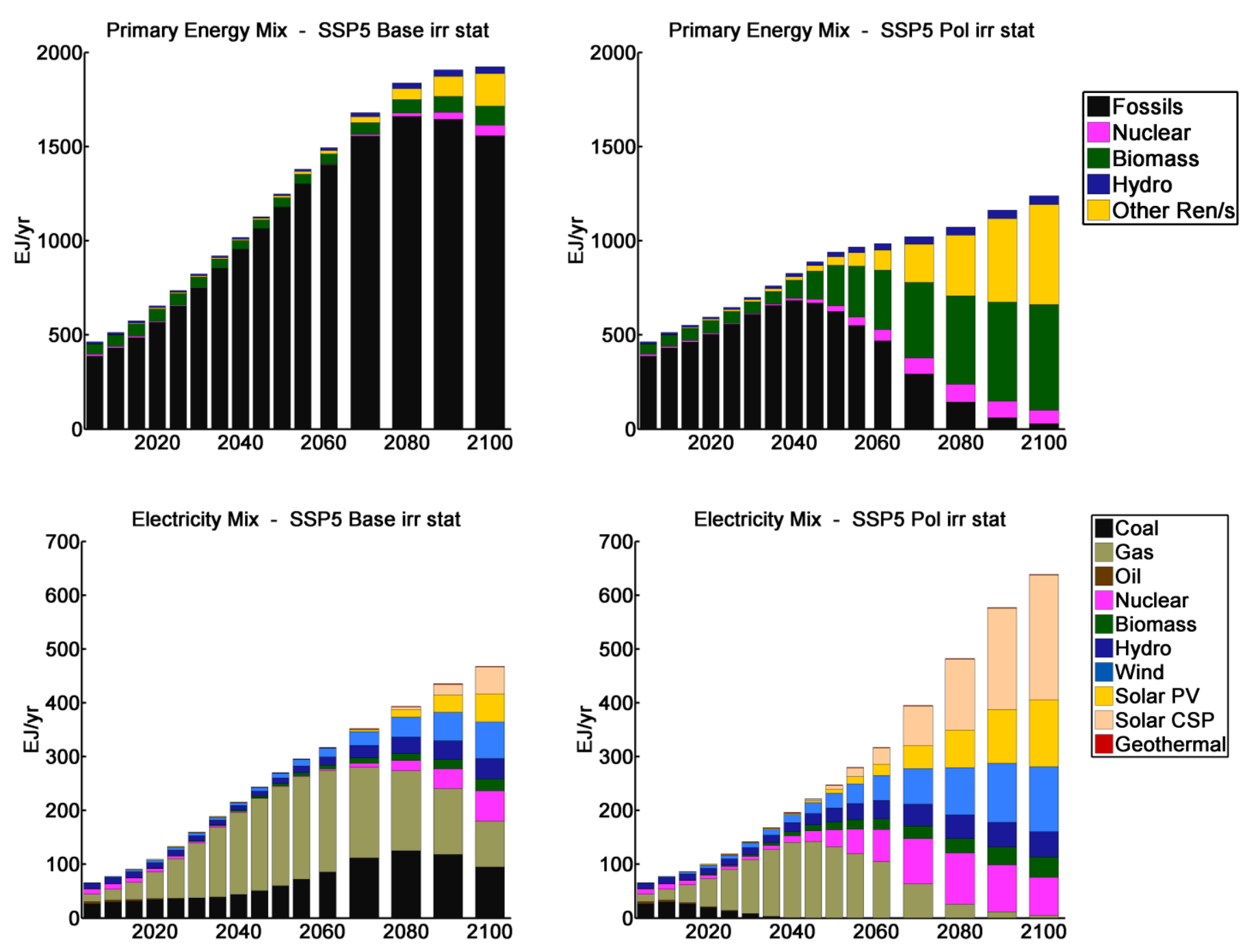

\begin{tabular}{|l|}
\hline Coal \\
Gas \\
Oil \\
Nuclear \\
Biomass \\
Hydro \\
Wind \\
Solar PV \\
Solar CSP \\
Geothermal \\
\hline
\end{tabular}
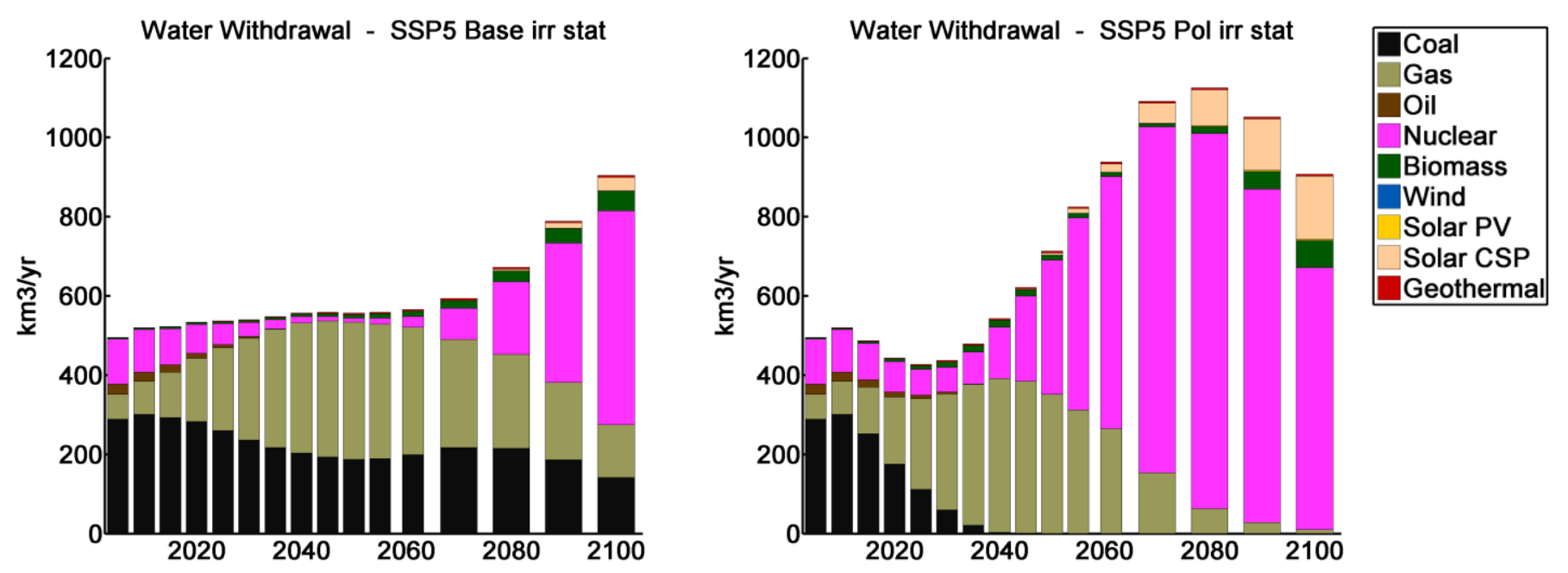

SM Figure 8: Primary energy, electricity, and electricity water withdrawal mixes for the SSP5 Baseline and Policy scenarios. 

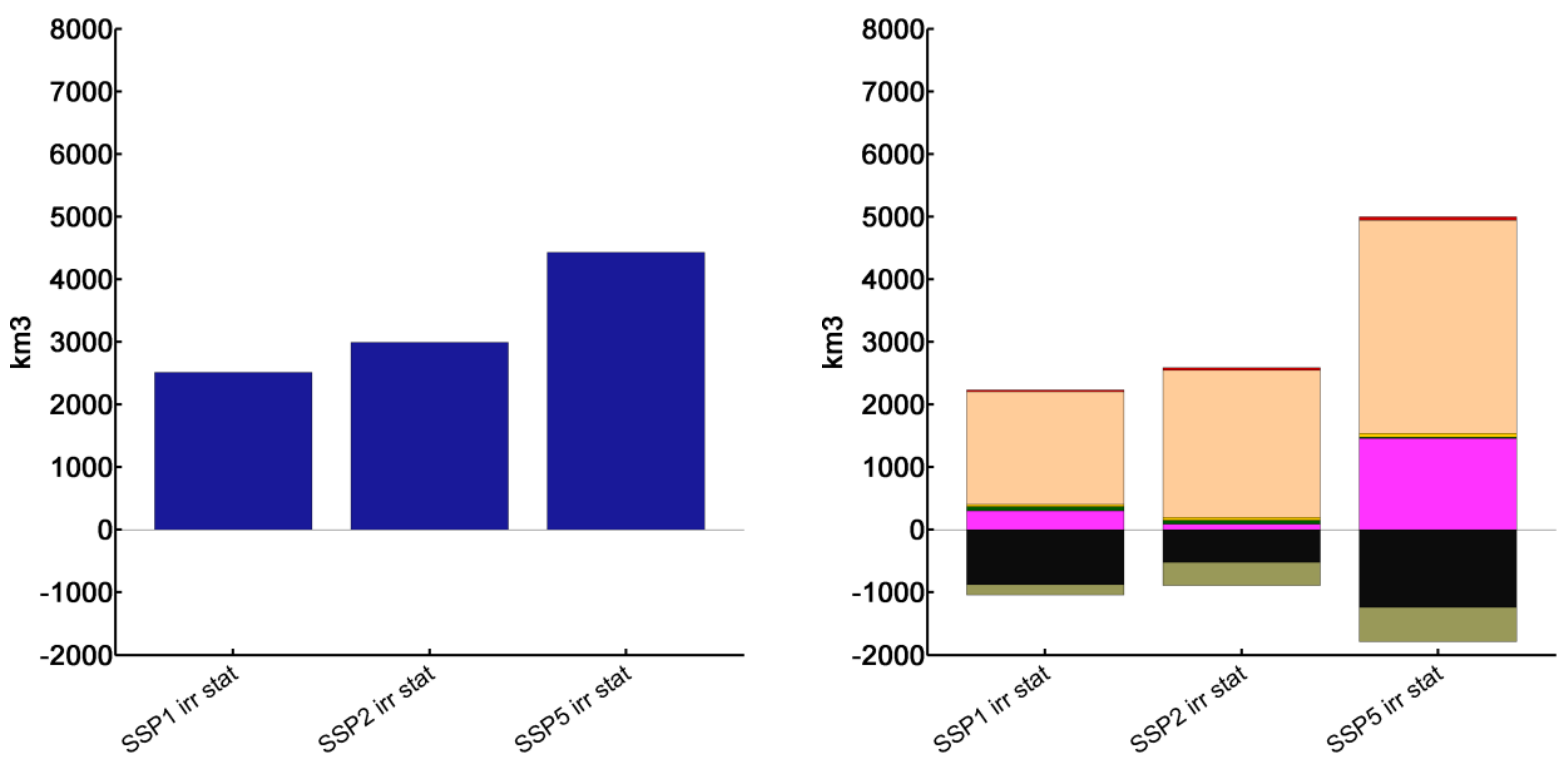

\begin{tabular}{|l|}
\hline Coal \\
\hline Gas \\
Oil \\
Nuclear \\
Biomass \\
Wind \\
Solar PV \\
Solar CSP \\
Geothermal \\
Hydro \\
\hline
\end{tabular}

SM Figure 9: Differences in water consumption between Baseline and Policy scenarios across SSPs. Negative numbers indicate lower values in the Policy scenarios compared to the equivalent Baseline scenarios. 


\subsection{Effects of combined socio-economic and water policy assumptions}
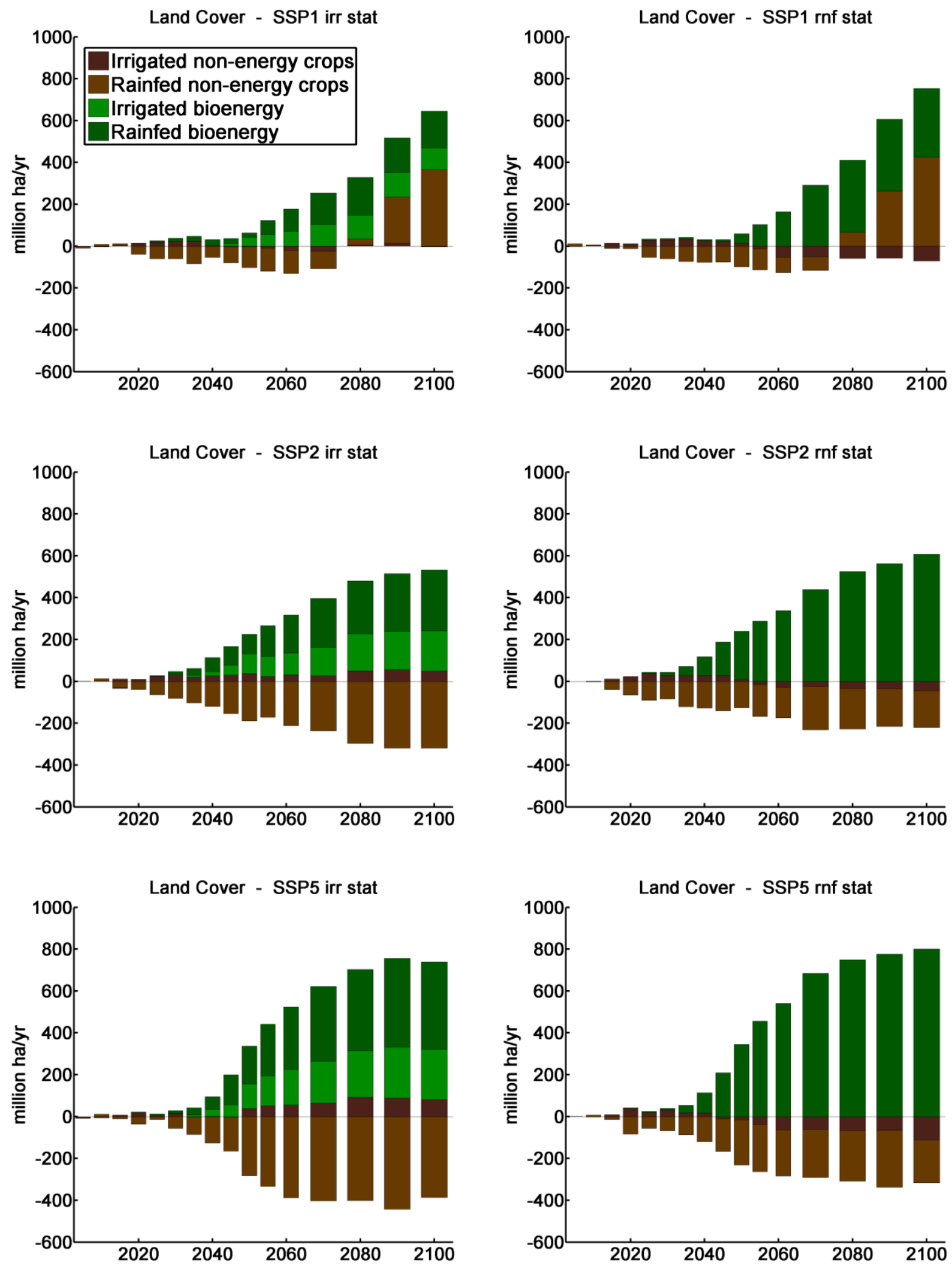

SM Figure 10: Difference in land cover between the Baseline and Policy scenarios across SSPs and water policy scenarios (Policy minus Baseline). Negative numbers indicate lower values in the Policy scenarios compared to the equivalent Baseline scenarios. 

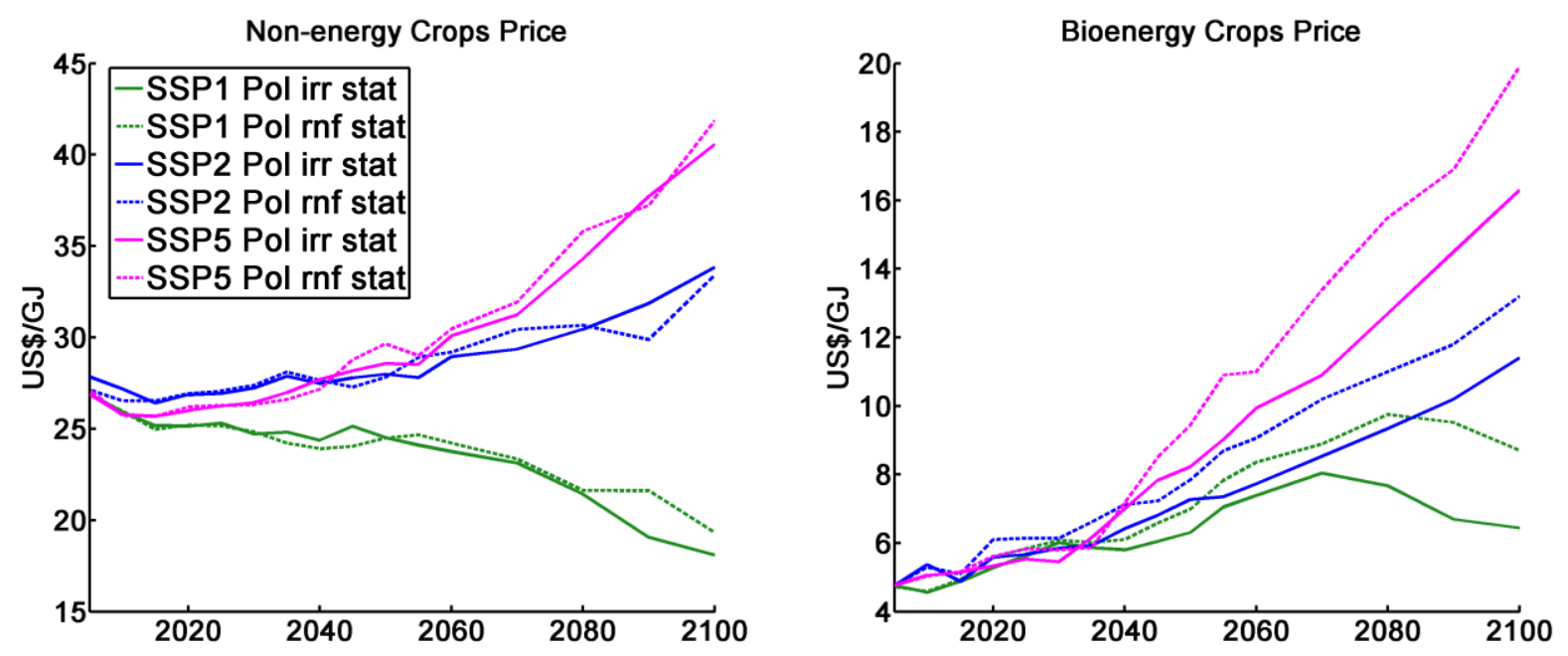

SM Figure 21: Non-energy and bioenergy crop prices for the Policy scenarios across SSPs and water policy scenarios. 

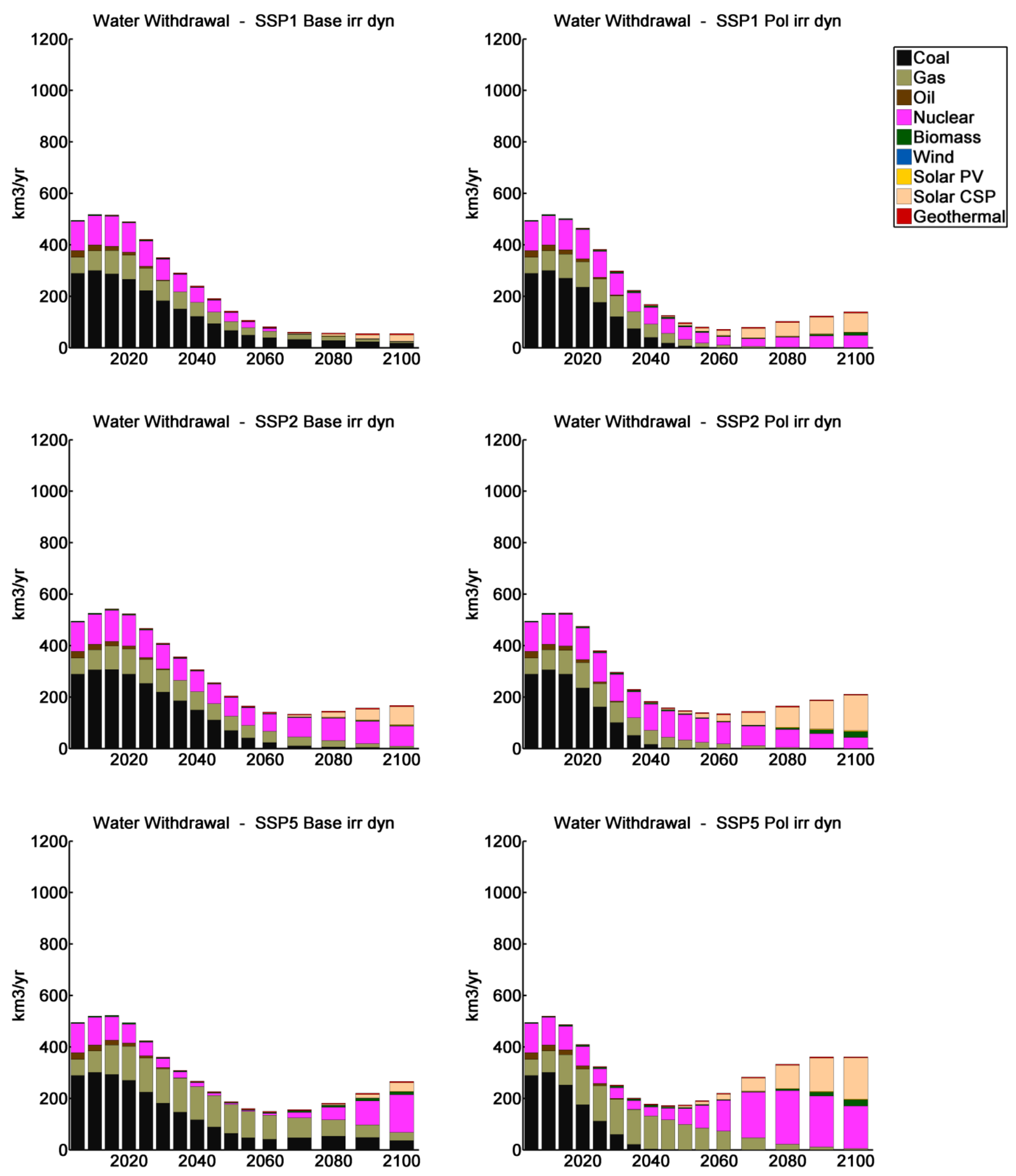

SM Figure 32: Electricity water withdrawal mixes for Baseline and Policy scenarios across SSPs for the dynamic cooling shares case. 


\section{References}

Bauer, N., Calvin, K., Emmerling, J., Fricko, O., Fujimori, S., Hilaire, J., Eom, J., Krey, V., Kriegler, E., Mouratiadou, I., de Boer, H.S., van den Berg, M., Carrara, S., Daioglou, V., Drouet, L., Edmonds, J., Gernat, D., Havlik, P., Johnson, N., Klein, D., Kyle, P., Marangoni, G., Masui, T., Pietzcker, R.C., Strubegger, M., Wise, M., Riahi, K., Van Vuuren, D.P., submitted. Shared Socio-Economic Pathways of the Energy Sector Quantifying the Narratives. Glob. Environ. Change.

Bauer, N., Klein, D., Luderer, G., Hilaire, J., Leimbach, M., Mouratiadou, I., Strefler, J., Dietrich, J.P., Humpenoder, F., Lotze-Campen, H., Popp, A., Müller, C., Kriegler, E., 2014. Climate change stabilization and the energy-land nexus, in: Proceedings of the 2014 International Energy Workshop. Presented at the 2014 International Energy Workshop, Beijing.

Biemans, H., Haddeland, I., Kabat, P., Ludwig, F., Hutjes, W.A., Heinke, J., von Bloh, W., Gerten, D., 2011. Impact of reservoirs on river discharge and irrigation water supply during the 20th century. Water Resour. Res. 47, W03509. doi:10.1029/2009WR008929

Biemans, H., Hutjes, R.W.A., Kabat, P., Strengers, B.J., Gerten, D., Rost, S., 2009. Effects of Precipitation Uncertainty on Discharge Calculations for Main River Basins. J. Hydrometeorol. 10, 1011-1025. doi:10.1175/2008JHM1067.1

Bijl, D.L., Bogaart, P.W., Kram, T., de Vries, B.J.M., van Vuuren, D.P., 2016. Long-term water demand for electricity, industry and households. Environ. Sci. Policy 55, Part 1, 75-86. doi:10.1016/j.envsci.2015.09.005

Bonsch, M., Popp, A., Biewald, A., Rolinski, S., Schmitz, C., Weindl, I., Stevanovic, M., Högner, K., Heinke, J., Ostberg, S., Dietrich, J.P., Bodirsky, B., Lotze-Campen, H., Humpenöder, F., 2015. Environmental flow provision: Implications for agricultural water and land-use at the global scale. Glob. Environ. Change 30, 113-132. doi:10.1016/j.gloenvcha.2014.10.015

Bonsch, M., Humpenöder, F., Popp, A., Bodirsky, B., Dietrich, J.P., Rolinski, S., Biewald, A., Lotze-Campen, H., Weindl, I., Gerten, D., Stevanovic, M., 2014. Trade-offs between land and water requirements for large-scale bioenergy production. Glob. Change Biol. Bioenergy 11-24. doi:10.1111/gcbb.12226

Byers, E.A., Hall, J.W., Amezaga, J.M., 2014. Electricity generation and cooling water use: UK pathways to 2050. Glob. Environ. Change 25, 16-30. doi:10.1016/j.gloenvcha.2014.01.005

Davies, E.G.R., Kyle, P., Edmonds, J.A., 2013. An integrated assessment of global and regional water demands for electricity generation to 2095. Adv. Water Resour. 52, 296-313. doi:10.1016/j.advwatres.2012.11.020

Dellink, R., Chateau, J., Lanzi, E., Magné, B., in press. Long-term economic growth projections in the Shared Socioeconomic Pathways. Glob. Environ. Change. doi:10.1016/j.gloenvcha.2015.06.004

Dietrich, J.P., Popp, A., Lotze-Campen, H., 2013. Reducing the loss of information and gaining accuracy with clustering methods in a global land-use model. Ecol. Model. 263, 233-243. doi:10.1016/j.ecolmodel.2013.05.009

Dietrich, J.P., Schmitz, C., Lotze-Campen, H., Popp, A., Müller, C., 2014. Forecasting technological change in agriculture-An endogenous implementation in a global land use model. Technol. Forecast. Soc. Change 81, 236-249. doi:10.1016/j.techfore.2013.02.003

EDGAR, 2011. Global Emissions EDGAR v4.2 [WWW Document]. URL http://edgar.jrc.ec.europa.eu/overview.php?v=42 (accessed 1.25.13).

FAOSTAT, 2013. Database Collection of the Food and Agriculture Organization of the United Nations. 
Farquhar, G.D., Caemmerer, S. von, Berry, J.A., 1980. A biochemical model of photosynthetic CO2 assimilation in leaves of C3 species. Planta 149, 78-90. doi:10.1007/BF00386231

Foley, J.A., Ramankutty, N., Brauman, K.A., Cassidy, E.S., Gerber, J.S., Johnston, M., Mueller, N.D., O/'Connell, C., Ray, D.K., West, P.C., Balzer, C., Bennett, E.M., Carpenter, S.R., Hill, J., Monfreda, C., Polasky, S., Rockstrom, J., Sheehan, J., Siebert, S., Tilman, D., Zaks, D.P.M., 2011. Solutions for a cultivated planet. Nature 478, 337-342. Förster, H., Lilliestam, J., 2010. Modeling thermoelectric power generation in view of climate change. Reg. Environ. Change 10, 327-338. doi:10.1007/s10113-009-0104-x

Hejazi, M., Edmonds, J., Clarke, L., Kyle, P., Davies, E., Chaturvedi, V., Wise, M., Patel, P., Eom, J., Calvin, K., Moss, R., Kim, S., 2014. Long-term global water projections using six socioeconomic scenarios in an integrated assessment modeling framework. Technol. Forecast. Soc. Change 81, 205-226. doi:10.1016/j.techfore.2013.05.006

IEA, 2013. Energy Balance of OECD Countries. International Energy Agency, Paris, France.

IEA, 2007a. Energy Balance of Non-OECD Countries. International Energy Agency, Paris, France.

IEA, 2007b. Energy Balance of OECD Countries. International Energy Agency, Paris, France.

Jägermeyr, J., Gerten, D., Heinke, J., Schaphoff, S., Kummu, M., Lucht, W., 2015. Water savings potentials of irrigation systems: global simulation of processes and linkages. Hydrol. Earth Syst. Sci. 19, 3073-3091. doi:10.5194/hess-19-3073-2015

Kijne, J.W., Barker, R., Molden, D., 2003. Water productivity in agriculture: limits and opportunities for improvement. CAB International, Wallingford, UK; Cambridge, USA.

Klein, D., Luderer, G., Kriegler, E., Strefler, J., Bauer, N., Leimbach, M., Popp, A., Dietrich, J., Humpenöder, F., Lotze-Campen, H., Edenhofer, O., 2014. The value of bioenergy in low stabilization scenarios: an assessment using REMIND-MAgPIE. Clim. Change 123, 705718. doi:10.1007/s10584-013-0940-z

Krause, M., Lotze-Campen, H., Popp, A., Dietrich, J.P., Bonsch, M., 2013. Conservation of undisturbed natural forests and economic impacts on agriculture. Land Use Policy 30, 344-354. doi:10.1016/j.landusepol.2012.03.020

Kriegler, E., Bauer, N., Popp, A., Humpenöder, F., Leimbach, M., Strefler, J., Baumstark, L., Bodirsky, B.L., Hilaire, J., Klein, D., Mouratiadou, I., Weindl, I., Bertram, C., Dietrich, J.P., Luderer, G., Pehl, M., Pietzcker, R., Piontek, F., Lotze-Campen, H., Biewald, A., Bonsch, M., Giannousakis, A., Kreidenweis, U., Müller, C., Rolinski, S., Schultes, A., Schwanitz, V.J., Stevanovic, M. (in press) Fossil-fueled development (SSP5): an energy and resource intensive scenario for the $21^{\text {st }}$ century. Global Environmental Change.

Kyle, P., Davies, E.G.R., Dooley, J.J., Smith, S.J., Clarke, L.E., Edmonds, J.A., Hejazi, M., 2013. Influence of climate change mitigation technology on global demands of water for electricity generation. Int. J. Greenh. Gas Control 13, 112-123. doi:10.1016/j.ijggc.2012.12.006

Lehner, B., Döll, P., 2004. Development and validation of a global database of lakes, reservoirs and wetlands. J. Hydrol. 296, 1-22. doi:10.1016/j.jhydrol.2004.03.028

Lotze-Campen, H., Müller, C., Bondeau, A., Rost, S., Popp, A., Lucht, W., 2008. Global food demand, productivity growth, and the scarcity of land and water resources: a spatially explicit mathematical programming approach. Agric. Econ. 39, 325-338. doi:10.1111/j.1574-0862.2008.00336.x

Luderer, G., Leimbach, M., Bauer, N., Kriegler, E., Baumstark, L., Bertram, C., Giannousakis, A., Hilaire, J., Klein, D., Levesque, A., Mouratiadou, I., Pehl, M., Pietzcker, R., Piontek, F., Roming, N., Schultes, A., Schwanitz, V.J., Strefler, J., 2015. Description of the REMIND model (Version 1.6). Potsdam Institute for Climate Impact Research, Potsdam, Germany. 
Macknick, J., Newmark, R., Heath, G., Hallett, K.C., 2011. A Review of Operational Water Consumption and Withdrawal Factors for Electricity Generating Technologies. (No. NREL/TP-6A20-50900). National Renewable Energy Laboratory, Golden, Colorado.

Macknick, J., Sattler, S., Averyt, K., Clemmer, S., Rogers, J., 2012. The water implications of generating electricity: water use across the United States based on different electricity pathways through 2050. Environ. Res. Lett. 7, 45803.

Meinshausen, M., Raper, S.C.B., Wigley, T.M.L., 2011. Emulating coupled atmosphere-ocean and carbon cycle models with a simpler model, MAGICC6 - Part 1: Model description and calibration. Atmos Chem Phys 11, 1417-1456. doi:10.5194/acp-11-1417-2011

Molden, D., Oweis, T., Steduto, P., Bindraban, P., Hanjra, M.A., Kijne, J., 2010. Improving agricultural water productivity: Between optimism and caution. Compr. Assess. Water Manag. Agric. 97, 528-535. doi:10.1016/j.agwat.2009.03.023

Mouratiadou, I., Luderer, G., Bauer, N., Kriegler, E., 2015. Emissions and their drivers: sensitivity to economic growth and fossil fuel availability across world regions. Clim. Change 1-15. doi:10.1007/s10584-015-1368-4

Narayanan, B., Walmsley, T., 2008. Global Trade, Assistance. and Production: The GTAP 7 Data Base. Center for Global Trade Analysis, Purdue University.

OECD, 2012. OECD Environmental Outlook to 2050: The Consequences of Inaction. OECD Publishing, Paris.

O’Neill, B.C., Kriegler, E., Ebi, K.L., Kemp-Benedict, E., Riahi, K., Rothman, D.S., van Ruijven, B.J., van Vuuren, D.P., Birkmann, J., Kok, K., Levy, M., Solecki, W., 2015. The roads ahead: Narratives for shared socioeconomic pathways describing world futures in the $21 \mathrm{st}$ century. Glob. Environ. Change. doi:10.1016/j.gloenvcha.2015.01.004

Pietzcker, R.C., Stetter, D., Manger, S., Luderer, G., 2014. Using the sun to decarbonize the power sector: The economic potential of photovoltaics and concentrating solar power. Appl. Energy 135, 704-720. doi:10.1016/j.apenergy.2014.08.011

Ramsey, F.P., 1928. A Mathematical Theory of Saving. Econ. J. 38, 543-559.

Rosegrant, M.W., Ringler, C., Zhu, T., 2009. Water for Agriculture: Maintaining Food Security under Growing Scarcity. Annu. Rev. Environ. Resour. 34, 205-222. doi:10.1146/annurev.environ.030308.090351

Rost, S., Gerten, D., Bondeau, A., Lucht, W., Rohwer, J., Schaphoff, S., 2008. Agricultural green and blue water consumption and its influence on the global water system. Water Resour. Res. 44, W09405. doi:10.1029/2007WR006331

Schaphoff, S., Heyder, U., Ostberg, S., Gerten, D., Heinke, J., Lucht, W., 2013. Contribution of permafrost soils to the global carbon budget. Environ. Res. Lett. 8, 14026. doi:10.1088/1748-9326/8/1/014026

Sitch, S., Smith, B., Prentice, I.C., Arneth, A., Bondeau, A., Cramer, W., Kaplan, J.O., Levis, S., Lucht, W., Sykes, M.T., Thonicke, K., Venevsky, S., 2003. Evaluation of ecosystem dynamics, plant geography and terrestrial carbon cycling in the LPJ dynamic global vegetation model. Glob. Change Biol. 9, 161-185. doi:10.1046/j.1365-2486.2003.00569.x

van Vliet, M.T.H., Yearsley, J.R., Ludwig, F., Vogele, S., Lettenmaier, D.P., Kabat, P., 2012. Vulnerability of US and European electricity supply to climate change. Nat. Clim Change 2, 676-681. doi:10.1038/nclimate 1546

Vassolo, S., Döll, P., 2005. Global-scale gridded estimates of thermoelectric power and manufacturing water use. Water Resour. Res. 41, W04010. doi:10.1029/2004WR003360

Wada, Y., van Beek, L.P.H., Viviroli, D., Dürr, H.H., Weingartner, R., Bierkens, M.F.P., 2011. Global monthly water stress: 2. Water demand and severity of water stress. Water Resour. Res. 47, W07518. doi:10.1029/2010WR009792

Waha, K., van Bussel, L.G.J., Müller, C., Bondeau, A., 2012. Climate-driven simulation of global crop sowing dates: Simulation of global sowing dates. Glob. Ecol. Biogeogr. 21, 247-259. 